\title{
Protection induced by anti-PD-1 and anti-PD-L1 treatment in Leishmania amazonensis-infected BALB/c mice
}

Alessandra M. da Fonseca-Martins ${ }^{1,2}$, Tadeu D. Ramos ${ }^{1}$, Juliana E.S. Pratti ${ }^{1}$, Luan Firmino-Cruz', Daniel Claudio Oliveira Gomes ${ }^{4}$, Lynn Soong ${ }^{5}$, Elvira M. Saraiva ${ }^{2}$, Herbert L. de Matos Guedes ${ }^{*, 1,3,6}$

${ }^{1}$ Instituto de Biofísica Carlos Chagas Filho, Laboratório de Imunofarmacologia, Grupo de Imunologia e Vacinologia, Universidade Federal do Rio de Janeiro, Rio de Janeiro, RJ, Brazil.

2Paulo de Góes Microbiology Institute, Immunology Department, Universidade Federal do Rio de Janeiro, Rio de Janeiro, RJ, Brazil,

${ }^{3}$ Universidade Federal do Rio de Janeiro - Campus Duque de Caxias Professor Geraldo Cidade, RJ, Brazil.

${ }^{4}$ Núcleo de Doenças Infecciosas, Universidade Federal do Espírito Santo, ES, Brazil.

${ }^{5}$ Department of Microbiology and Immunology, Institute for Human Infections and Immunity, University of Texas Medical Branch, Galveston, TX, USA.

${ }^{6}$ Laboratório Interdisciplinar de pesquisas Médicas, Instituto Oswaldo Cruz, Fundação Oswaldo Cruz

${ }^{*}$ Author of correspondence.

Dr. Herbert Leonel de Matos Guedes

E-mail: herbert@biof.ufri.br, herbert@xerem.ufri.br, herbert@ioc.fiocruz.br

Universidade Federal do Rio de Janeiro, Instituto de Biofísica Carlos Chagas Filho, Laboratório de Imunofarmacologia, Grupo de Imunologia e Vacinologia, Rio de Janeiro, RJ, Brazil. Phone: +55213239-6509

Running title: PD-1/PD-L1 in L. amazonensis infection on BALB/c mice 


\section{Abstract}

Leishmaniasis is a neglected disease, for which current treatment presents numerous issues. Leishmania amazonensis is the etiological agent of cutaneous and diffuse cutaneous leishmaniasis. The roles of the programmed death-1 (PD-1) receptor on lymphocytes and its ligand (PD-L1) on antigen-presenting cells have been well studied in tumor and other infection models; but little is known about their roles in non-healing cutaneous leishmaniasis. Our previous report of $L$. amazonensis-induced PD-L1 expression on dendritic cells, in combination with decreased IFN- $\gamma$ production by CD4 ${ }^{+}$ T cells in C57BL/6 mice, led to a hypothesis that the formation of the PD-1/PD-L1 complex contributes to down-modulation of immune responses, especially $\mathrm{T}$ cell suppression, enabling parasite survival and persistence. In this study, we tested the therapeutic potential of anti-PD-1 and anti-PD-L1 monoclonal antibodies (MoAbs) against a non-healing $L$. amazonensis infection in BALB/c mice. We observed that $L$. amazonensis induced PD-1 expression on both $\mathrm{CD}^{+}$and $\mathrm{CD}^{+} \mathrm{T}$ cells, and that antiPD-1 and anti-PD-L1 treatment significantly increased IFN- $\gamma$-producing $\mathrm{CD}^{+}$and $\mathrm{CD}^{+} \mathrm{T}$ cells, respectively. Compared with infection controls, mice that received treatment with anti-PD-1 and anti-PD-L1, but not anti-PD-L2, displayed bigger lesions with significantly lower parasite loads. Treatment did not affect anti-Leishmania antibody or IL-10 production, but anti-PD-1 treatment reduced both IL-4 and TGF- $\beta$ production. Together, our results highlight the therapeutic potential of an anti-PD-1based treatment in promoting the reinvigoration of $\mathrm{T}$ cells for the control of parasite burden.

KEYWORDS: Leishmania amazonensis, PD-1, PD-L1, mAbs, Blocking antibody, IFN-Y 


\section{INTRODUCTION}

Leishmaniasis is a disease with global public health concerns, particularly in poor communities. Conventional treatments arose in the 1940s; however, many problems are associated with these medications, such as high toxicity, adverse side effects, and the increased incidence of drug-resistant parasites. At present, there are no vaccines available for human use, which makes the search for new molecular targets highly necessary ${ }^{1}$. Leishmania amazonensis infection can cause a diverse spectrum of the disease, including cutaneous (the most common), mucosal, and visceral leishmaniasis, as well as diffuse cutaneous leishmaniasis that is refractory to the conventional treatment ${ }^{2}$.

The programmed death-ligand 1 (PD-L1), a cell surface glycoprotein belonging to the B7 family is expressed on antigen-presenting cells such as neutrophils, macrophages, and dendritic cells. PD-L1 binds to the PD-1 receptor, which belongs to the CD28 family and is expressed on T cells, B cells, and myeloid cells ${ }^{3-5}$. The PD1/PD-L1 interaction leads to the suppression of T cells by affecting the gradual loss of cell activities including cytokine secretion (IFN- $\gamma$, IL-2, TNF- $\alpha$ ), decreasing the proliferative capacity, and finally, inducing $T$ cell apoptosis. ${ }^{6,7}$ The PD-L1 receptor is widely discussed in oncological studies, as it is selectively expressed in many tumors ${ }^{4,8,9}$ and in cells within the tumor microenvironment in response to inflammatory stimuli. ${ }^{10}$ PD-L1 is positively regulated in solid tumors, where it can inhibit cytokine production and the cytolytic activity of PD-1-expressing CD4+ and CD8+ T cells. ${ }^{4,11,12}$ PD-1/PD-L1-based monoclonal antibody (MoAb) therapy is currently in phase III clinical trials with promising results for treatment against bladder carcinoma ${ }^{13}$ and lung cancer $^{14}$. Programmed death-ligand 2 (PD-L2) is also a cell surface glycoprotein in the B7 family and plays a role similar to PD-L1, because it inhibits $T$ cell function by binding PD-1 to the controversy in different models. T cell suppression is also reversed when the receptor is blocked by a specific antibody, for example, in inducing oral tolerance. ${ }^{15-17}$

It has been shown that PD-1/PD-L1-mediated cellular exhaustion also occurs during the progression of chronic infectious diseases caused by viruses or protozoan parasites, such as AIDS, toxoplasmosis, and cutaneous leishmaniasis. 15,18-20 Liang and colleagues have reported that $L$. mexicana-infected PD-L $1^{-/-}$mice have increased production of IFN- $\gamma$ in T cells, reduced disease progression, and greater control of the parasite load when compared with infected wild-type (WT) mice. In PD-L2 ${ }^{-/-}$mice, 
however, there was an increased lesion size and increased parasite load compared to WT mice, which implies there are differing roles for PD-L1 and PD-L2 in regulating IFN- $\gamma$ production. These results also suggest the participation only of PD-L1 in the $T$ exhaustion process during L. mexicana infection. ${ }^{15}$

We have demonstrated that $L$. amazonensis infection of bone marrow-derived dendritic cells (BMDCs) from C57BL/6 and BALB/C mice induced PD-L1 expression. Furthermore, L. amazonensis infection of C57BL/6 mice induced suppression of the immune response through impaired IFN- $\gamma$-producing $\mathrm{CD}^{+} \mathrm{T}$ cells, which was not observed in PD-L1/- mice. ${ }^{21}$ In C57BL/6 mice, the lesion reaches a peak of growth during $L$. amazonensis infection, followed by a process of resolution of the disease, which shows that this mouse strain has a higher resistance to the parasite. In contrast, $B A L B / c$ mice develop a progressive lesion without healing, suggesting a greater susceptibility of these animals. Thus, we hypothesize that the use of anti-PD-1 and anti-PD-L1 MoAbs would have the potential to reverse the $\mathrm{T}$ cell suppression phenotype observed in BALB/c mice. Therefore, here we investigate the expression of PD-1 and PD-L1 upon L. amazonensis infection in BALB/C mice, and evaluate the use of MoAbs against PD-1, PD-L1 and PD-L2 as therapies for the severe form of leishmaniasis caused by L. amazonensis.

\section{MATERIALS AND METHODS}

\section{Experimental Animals}

Female BALB/c mice, 6-8 weeks old, from the Núcleo de Animais de Laboratório (Universidade Federal Fluminense, Rio de Janeiro, Brazil), were housed in Ventilife mini-isolators (Alesco, Brazil) and kept under controlled temperature and light conditions. All of the animal experiments were performed in strict accordance with the Brazilian animal protection law (Lei Arouca number 11.794/08) of the National Council for the Control of Animal Experimentation (CONCEA, Brazil). The protocol was approved by the Committee for Animal Use of the Universidade Federal do Rio de Janeiro (Permit Number: 161/18).

\section{Culture of Parasites}

Infective promastigotes of $L$. amazonensis (MHOM/BR/75/Josefa) were obtained from infected BALB/C mouse lesions and were used until the $5^{\text {th }}$ culture 
passage as promastigotes at $26^{\circ} \mathrm{C}$ in $\mathrm{M}-199$ medium (Cultilab) supplemented with $20 \%$ heat-inactivated fetal bovine serum (FBS) (Cultilab).

\section{In vivo Infection and Treatment}

$B A L B / c$ mice were infected subcutaneously in the right hind footpad with $2 \times 10^{6}$ stationary-phase promastigotes of $L$. amazonensis in $20 \mu \mathrm{l}$ PBS. The following antibodies were administered intraperitoneally at $100 \mu \mathrm{g}$ in $100 \mu \mathrm{l} \mathrm{PBS}$; anti-PD-L1 (BMS-936559, Bristol-Myers Squibb), anti-PD-L2 (B7-DC, clone TY25, catalog \# BE0112, Bioxcell), and anti-PD-1 (CD279, clone RMP1-14, catalog \# BE0146, Bioxcell). The first injection was given at 7 days post-infection. Two treatment protocols were assessed: (i) inoculation once a week for 49 days with a total of 6 doses; and (ii) twice a week for 56 days with a total of 12 doses. Control animals received $100 \mu$ PBS intraperitoneally also at 7 days post-infection and in accordance with the two treatment protocols. For both treatments, the last dose was administered 5 days prior to the euthanasia of the animals. Footpad thickness was measured weekly by using a direct-reading Vernier caliper.

\section{Parasite Load Quantification}

After the mice were euthanized, the infected paws were removed, weighed, macerated with a tissue mixer, the homogenate diluted into 96-well culture plates (Jet Biofil, China) and incubated at $26^{\circ} \mathrm{C}$ for 7 and 15 days. Promastigote cultures were examined via optical microscope (Olympus, Japan), and the last well containing promastigotes in the limiting dilution assay was recorded to calculate the parasite load.

\section{Cell Staining for Flow Cytometry}

Lymph nodes were removed and macerated with a tissue mixer; cells (1x106/well in a 24 -well plate) were cultured for $4 \mathrm{~h}$ at $37^{\circ} \mathrm{C}$ with lonomycin $(10 \mathrm{ng} / \mathrm{ml}$, Sigma-Aldrich), Brefeldin (5 mg/ml, Biolegend) and PMA (phorbol 12- myristate 13acetate, $10 \mathrm{ng} / \mathrm{ml}$, Sigma-Aldrich). All centrifugation steps were performed at $4^{\circ} \mathrm{C}$. Cells were washed with PBS and blocked with $50 \mu \mathrm{l} /$ well (Human FcX, BioLegend) for $15 \mathrm{~min}$. After which, $50 \mu \mathrm{l} /$ well of the staining antibody pool was added and incubated for $30 \mathrm{~min}$ at $4^{\circ} \mathrm{C}$. Cells were washed with buffer solution (PBS with 5\% FBS) at 400 $\mathrm{g}$ for $5 \mathrm{~min}$, then fixed and permeabilized (FoxP3 permeabilization/fixation kit; eBiosicence) according to the manufacturer's protocol. Cells were washed again with 
buffer solution and resuspended in the same solution. For intracellular staining, the following antibodies were added (all used at $0.1 \mu \mathrm{g} / \mathrm{ml}$ ) and incubated for $1 \mathrm{~h}$ at $4^{\circ} \mathrm{C}$ in the dark: CD3 (anti-CD3-APC-780; clone 145-2C11, Biolegend), CD4 (anti-CD4-PECy7; clone RM4-5, Biolegend), CD8 (anti-CD8-PerCP; clone 53-6.7, Biolegend), PD1 (anti-PD-1-FITC; clone J43, eBiosciences), CD25 (anti CD25-PE; clone P4A10, eBioscience), and intracellular IFN- $\gamma$ (anti-IFN- $\gamma$-APC; clone XMG1.2, eBiosciences) and FoxP3 (clone FJK-16s; eBioscience). Cells were washed and resuspended in 150 $\mu \mathrm{l}$ buffer solution, and stored in the dark at $4^{\circ} \mathrm{C}$ until acquisition. Cells were analyzed on a BD FACS CANTO II flow cytometer; data from 100,000 events were captured from cells acquired on $\mathrm{CD}^{+}$and analyzed with FlowJo ${ }^{\circledR}$ software (BD-Becton, Dickinson \& Company).

\section{Analysis of Cytokines}

The supernatants of the paw maceration were assayed for IL-4, IL-10, and TGF$\beta$ cytokines by specific ELISAs using a standard protocol (BD OptEIA).

\section{Dosage of Immunoglobulins}

Soluble L. amazonensis antigen ( $\mathrm{LaAg})$ was obtained from stationary phase promastigotes, which were washed 3 times in PBS, freeze-thawed for 3 cycles, lyophilized, stored at $-20^{\circ} \mathrm{C}$ and reconstituted with PBS just prior to use. The 96-well plates were coated with $\mathrm{LaAg}\left(1 \mu \mathrm{g} /\right.$ well) overnight at $4^{\circ} \mathrm{C}$, blocked with $\mathrm{PBS} / 5 \%$ milk/0.05\% Tween 20 (Sigma-Aldrich) for $2 \mathrm{~h}$, and washed 3 times with PBS/0.05\% Tween 20. The mouse serum samples (1:250 diluted in PBS/5\% milk/0.05\% Tween 20) were added. The plates were incubated at room temperature for $1 \mathrm{~h}$ and washed with PBS/0.05\% Tween 20. Anti-IgM or anti-IgG-HRP (Southern Biotech) were added $(1: 2000)$ for $1 \mathrm{~h}$ at room temperature. After washing, the color was developed with a TMB solution (Life Technologies) and stopped with $1 \mathrm{M} \mathrm{HCl}$.

\section{Data Analysis}

Results are expressed as mean \pm SD with confidence level $p \leq 0.05$. For lesion development analysis, a two-way ANOVA with a Bonferroni post-test was used. For multiple comparisons, a one-way ANOVA followed by Tukey pairing was performed. Paired t-test analysis was done as indicated in the figure legends. Data analysis was performed using GraphPad Prism ${ }^{\circledR} 5.00$ software. 


\section{RESULTS}

\section{L. amazonensis infection induces PD-1 expression on CD4+ and CD8+ T cells.}

Previous studies by our group have demonstrated that in footpads and lymph nodes of $L$. amazonensis-infected C57BL/6 mice, there is increased expression of PD1 on $\mathrm{CD}^{+} \mathrm{T}$ cells in comparison to naïve uninfected mice. ${ }^{21}$ Given that the disease profile of $L$. amazonensis infection in C57BL/6 and BALB/c mice are different, in that BALB/c mice develop more progressive disease than C57BL/6 mice, we decided to evaluate the expression of PD-1 in lymph node cells of $L$. amazonensis-infected BALB/c mice. The data showed an increase in the percentage (Fig. 1a, c) and absolute number (Fig. 1b) of PD-1+ CD4 ${ }^{+}$and $C D 8^{+}$T cells in infected compared to uninfected BALB/c mice.

\section{Anti-PD-1 or anti-PD-L1 MoAb treatment reduces parasite loads without affecting lesion growth in mice.}

As we observed that PD-1 was upregulated during $L$. amazonensis infection, we next assessed the effect of treatment with the anti-PD-1, anti-PD-L1, and anti-PDL2 blocking antibodies on the disease profile. First, L. amazonensis-infected BALB/C mice were treated with the individual MoAbs (100 $\mu \mathrm{g}$ each/mice) once weekly, beginning at 7 days post-infection, receiving a total of 6 doses. The footpad thickness was measured weekly, and the parasite load was determined after 49 days of treatment. We found that this therapy was not effective in modifying the lesion development profile (Suppl. Fig. 1a) or the parasite load (Suppl. Fig. 1b) compared to control mice injected with PBS.

In the second treatment protocol, mice were given individual MoAbs twice weekly, beginning at 7 days post-infection and receiving a total of 12 doses during the 56 day observation period. We found that although the lesion sizes (Fig. 2a) were increased during anti-PD1 and anti-PD-L1 treatment, the parasite loads were significantly decreased after anti-PD-1 or anti-PD-L1 treatment (Fig. 2b), Suppl. Fig. 2b). Anti-PD-L2 treatment did not show any significant effect (Suppl. Fig. 2). These results suggest the possibility of using the anti-PD-1 and anti-PD-L1 MoAb therapies to decrease parasitic load. 


\section{Induction of IFN- $\gamma$ from CD4+ and CD8+ ${ }^{+}$cells after MoAb treatment.}

Focusing on the twice a week treatment protocol, we then examined the mechanism underlying parasite load reduction in anti-PD-1 or anti-PD-L1-treated mice by measuring the IFN- $\gamma$ production of $\mathrm{CD}^{+}$and $\mathrm{CD} 4^{+} \mathrm{T}$ cells from the draining lymph nodes. It is documented in murine models of $L$. major infection that the expression of cytokines such as IL-12 and IFN- $\gamma$ by Th1 contributes to host protection, whereas IL4, IL-5, and IL-10 expression by Th2 contributes to host susceptibility. ${ }^{22,23}$ In the murine L. amazonensis infection model, we and others have shown that impaired IFN$\gamma$ production and insufficient macrophage activation favor parasite survival and persistence. ${ }^{22-25}$ In our treatment studies, we found more CD3 ${ }^{+} C D 8^{+} T$ cells in the $L$. amazonensis-infected mice compared to uninfected mice (Fig. 1a), but there were no significant difference in the percentage and absolute number of $\mathrm{CD} 3^{+} \mathrm{CD} 8^{+} \mathrm{T}$ cells between the MoAb-treated and the PBS-injected groups (Fig. 3a, b). However, both, percentage and absolute number of IFN- $\boldsymbol{\gamma}$-producing $\mathrm{CD} 3^{+} \mathrm{CD} 8^{+} \mathrm{T}$ cells $\left(\mathrm{IFN}-\boldsymbol{\gamma}^{+} \mathrm{CD} 8^{+}\right.$ T cells) were significantly increased in anti-PD-1 or anti-PD-L1-treated mice when compared to the PBS-injected group (Fig. 3c, d, e).

As the percentage and number of $\mathrm{PD}-1^{+} \mathrm{CD} 8^{+} \mathrm{T}$ cells were increased in $L$. amazonensis infection (Fig. 1), we next examined whether the IFN-r production could also be affected in the CD8 ${ }^{+} \mathrm{T}$ cells lacking PD-1 (PD-1-CD8 ${ }^{+}$) during MoAb treatment. Similar to the total CD3 ${ }^{+} \mathrm{CD} 8^{+} \mathrm{T}$ cells, the PD-1-CD8 ${ }^{+} \mathrm{T}$ cells of both groups of MoAbtreated mice presented a higher percentage of IFN- $\gamma$ expression, but there was not a significantly higher number of IFN- $\gamma^{+} \mathrm{PD}-1^{-} \mathrm{CD} 8^{+} \mathrm{T}$ cells compared to the PBS-injected group (Fig. 4a, b, c).

Regarding PD $-1^{+} \mathrm{CD} 8^{+} \mathrm{T}$ cells not expressing IFN- $\gamma\left(\right.$ IFN $\left.-\gamma-\mathrm{PD}-1^{+} \mathrm{CD} 8^{+}\right)$, there was a significant decrease in the percentage of these cells in anti-PD-L1-treated mice compared to the PBS-injected group, without any effect on the absolute numbers (Figure $4 \mathrm{~d}, \mathrm{e}$ ). We did observe an increase in the IFN- $\gamma$-expressing PD-1+CD8+ T cells in both the percentage and absolute number of anti-PD-1-treated mice, but there was no significant difference in anti-PD-L1-treated mice compared to the PBS-injected group (Fig. 4f, g).

We also investigated the profile of $\mathrm{CD}^{+} \mathrm{T}$ cells and found no major differences between the MoAb-treated and PBS-injected groups regarding the percentage and number of $\mathrm{CD}^{+}{ }^{+} \mathrm{CD} 4^{+} \mathrm{T}$ cells (Fig. $5 \mathrm{a}$, b). Like the $\mathrm{CD} 3^{+} \mathrm{CD} 8^{+} \mathrm{T}$ cells, the percentage 
of $\mathrm{CD}^{+} \mathrm{T}$ cells producing IFN- $\boldsymbol{\gamma}$ was significantly increased after treatment with antiPD-1 and anti-PD-L1 (Fig. 5c, d), however, a significant increase in the number of IFN$\gamma^{+}$-producing CD4+ $\mathrm{T}$ cells was observed in the anti-PD-1 treatment (Fig. 5e).

Unlike the PD-1 ${ }^{-} \mathrm{CD}^{+} \mathrm{T}$ cells, MoAb treatment had no effect on the IFN- $\gamma$ production by PD-1 CD4+ T cells (Fig. 6a, b, c). Again, opposite to what was observed in the IFN- $\gamma^{-}$PD $-1+C D 8+T$ cells, there was a significantly higher percentage of IFN- $\boldsymbol{\gamma}^{-}$ PD-1+CD4+ T cells in anti-PD-L1-treated mice, with no difference on the absolute number of these cells (Fig. 6d, e). Additionally, a significant increase in the percentage of IFN- $\gamma$-producing PD- $1^{+} \mathrm{CD} 4^{+} \mathrm{T}$ cells $\left(\mathrm{IFN}-\gamma^{+} \mathrm{PD}-1^{+} \mathrm{CD} 4^{+}\right)$was found for both MoAbtreated groups compared to the PBS-infected group, which was not observed in the number of cells (Fig. 6f, g).

Altogether, our results suggest that anti-PD-1 and anti-PD-L1 MoAb treatment stimulated the production of IFN- $\gamma$ in both $\mathrm{CD}^{+}$and $\mathrm{CD}^{+} \mathrm{T}$ cells, which may be one of the possible mechanisms for the control of parasite load.

\section{Anti-PD-1 treatment reduces IL-4 and TGF- $\beta$.}

As IFN- $\gamma$ production was induced by the MoAb treatment, we tested the effect of treatment on the modulation of the cytokines, IL-4, IL-10 and TGF- $\beta$, at the site of L. amazonensis infection. Only anti-PD-1 treatment significantly decreased IL-4 (Fig. 7a) and TGF- $\beta$ (Fig. 7b) production in situ compared to the PBS-injected control group. No alteration in the IL-10 levels was found after MoAb treatment (Fig. 7c). Finally, we demonstrated that treatment with the MoAbs did not affect the production of antiLeishmania specific IgM or IgG antibodies as assessed in the blood sera (Suppl. Fig. $4 \mathrm{a}, \mathrm{b})$. Altogether, our results suggest that anti-PD-1 MoAb treatment modulates the production of IFN-r in CD4 ${ }^{+} \mathrm{T}$ and $\mathrm{CD} 8^{+} \mathrm{T}$ cells, but anti-PD-L1 only affects CD8 ${ }^{+} \mathrm{T}$ cells.

\section{DISCUSSION}

The use of leukocyte receptor blockers in immunotherapy has been extensively studied in oncology. ${ }^{26}$ One of the clinical trials concerning the systemic administration of therapeutic antibodies to block PD-1 or PD-L1 has produced promising results for the treatment of several tumors. ${ }^{27,28}$ However, the use of this therapy is still relatively limited in non-healing leishmaniasis. 
L. amazonensis infection in C57BL/6 mice induced expression of PD-1 on CD4+ T cells (de Matos Guedes et al, submitted); however, in BALB/c mice the expression of PD-1 was induced on both $\mathrm{CD}^{+}$and $\mathrm{CD}^{+} \mathrm{T}$ cells prompting a more severe impairment of IFN- $\gamma$ production. For $L$. major infection in arginase-deficient mice, deficiency in T cell activation resulted in increased PD-1 expression, impairing the immune response and inducing $T$ cell exhaustion. ${ }^{29}$ In dogs injected with $L$. infantum antigens, PD-L1/PD-1 blockade with specific antibodies recovered the proliferation of $\mathrm{CD}^{+}$and $\mathrm{CD}^{+} \mathrm{T}$ cells, in addition to the production of IFN- $\gamma$ by CD4 ${ }^{+} \mathrm{T}$ cells. ${ }^{30} \mathrm{In}$ studies of $L$. donovani infection in BALB/C mice, the parasite induced the initial expansion of IFN- $\gamma$-producing $\mathrm{CD}^{+}$and $\mathrm{CD}^{+} \mathrm{T}$ cells in the acute phase of the disease, the frequency of which was reduced after 21 days post-infection even with a robust parasite presence. In this model, blocking PD-L1 resulted in the restoration of $\mathrm{CD}^{+}$and $\mathrm{CD}^{+} \mathrm{T}$ cell responses, leading to a reduction in parasite load. ${ }^{31}$ In view of these studies, our results presented herein show that L. amazonensis infection interferes in the production of IFN- $\gamma$ by both $\mathrm{CD}^{+}$and $\mathrm{CD} 8^{+} \mathrm{T}$ cells.

Recently, the presence of PD-1 and PD-L1 was detected in a patient with diffuse cutaneous leishmaniasis caused by $L$. amazonensis. ${ }^{32}$ Based on the induction of PD-1 and PD-L1 by Leishmania infection, the blocking of these molecules may be a new strategy to treat leishmaniasis.

The use of anti-PD-1 and anti-PD-L1 antibodies in clinical cancer treatment studies, such as in pancreatic tumor, were administered at doses between 10 and 200 $\mu \mathrm{g}$ every three days. ${ }^{33-35}$ In our study, we tested a lower therapeutic dose of $100 \mu \mathrm{g}$ of the anti-PD-L1, anti-PD-L2 and anti-PD-1 antibodies once a week. However, our data revealed that this was insufficient in reducing the lesion size or parasite load. Therefore, the dosage of the treatment, in terms of the concentration and frequency of administration are important considerations. Thus, we increased the administration to twice a week, and observed that although the lesion size was increased, the parasite load in the infected footpads, in the spleen and in the draining lymph nodes that received therapy with anti-PD-1 and anti-PD-L1 were controlled.

In L. major infection, only treatment with $1 \mathrm{mg} /$ dose of the anti-PD-1 antibody weekly in infected arginase-deficient mice led to complete resolution of the chronic skin lesion and resistance to infection. ${ }^{29} \mathrm{~A}$ similar result was found when using the anti-PD-L1 antibody in mice challenged with L. donovani amastigotes, as these mice showed a reduction of up to $87 \%$ of the parasite load in the spleen. ${ }^{36}$ The susceptibility 
of the $\mathrm{C} 57 \mathrm{BL} / 10$ and $\mathrm{C} 57 \mathrm{BL} / 6$ mice to infection by $L$. amazonensis is related to the absence of Th1 type cellular immune response and not controlled exclusively by Th2 cells. ${ }^{37,38}$ In BALB/c mice, this susceptibility is related to Th2 type cellular immune response. ${ }^{39,40}$

In this study, we observed that the production of IFN- $\gamma$ was higher in CD8 ${ }^{+} \mathrm{T}$ lymphocytes, both in percentage and number of cells after treatment with the anti-PD1 and anti-PD-L1 MoAbs. We also detected an increase in the percentage of IFN- $\gamma$ producing $\mathrm{CD}^{+} \mathrm{T}$ lymphocytes after both treatments. However, when looking at the number of IFN- $\gamma$-producing $\mathrm{CD}^{+}{ }^{+} \mathrm{T}$ cells only in mice treated with anti-PD-1 a significant increase was observed. These results suggest that treatment with anti-PD1 , acting directly on the lymphocytes, is more competent in invigorating CD4 ${ }^{+} \mathrm{T}$ lymphocytes than-the anti-PD-L1 therapy, the target of which is in the antigenpresenting cells. Our data indicate that the increase of IFN- $\gamma$ is one of the possible mechanisms of the therapeutic efficacy of these monoclonal antibody therapies, mainly by CD8 ${ }^{+} \mathrm{T}$ and partially by CD4+ $\mathrm{T}$ lymphocytes.

The PD-1/PD-L1 ratio is very important in suppressing the CD8+ $T$ cell response during $L$. donovani infection. ${ }^{36}$ In a study of dogs with symptomatic visceral leishmaniasis by $L$. infantum, these animals were shown to have a five-fold reduction in the proliferative capacity of $\mathrm{CD}^{+} \mathrm{T}$ cells and a reduction of up to three-fold in the ability of these cells to produce IFN- $\gamma$. After administration of specific monoclonal antibody therapy, PD-1 blockade significantly increased the proliferative capacity of $\mathrm{CD}^{+}$and $\mathrm{CD}^{+} \mathrm{T}$ cell populations, and recovered IFN- $\gamma$ production in the $\mathrm{CD}^{+}$ population. In addition, T cell depletion during visceral leishmaniasis was associated with elevated expression of PD-1, which could be identified before the onset of the disease and is considered a determining factor for symptomatic onset. ${ }^{30}$ In another study of canine visceral leishmaniasis, it was observed that as the disease progressed, there was a decrease in $\mathrm{CD}^{+}{ }^{+} \mathrm{T}$ cell proliferation and also a reduction of IFN- $\gamma$ production in response to $L$. infantum antigens. ${ }^{39}$

These findings are reinforced by studies in which anti-PD-1 and anti-PD-L1 therapy reverts the ability of $\mathrm{CD}^{+} \mathrm{T}$ lymphocytes to produce IFN- $\gamma$ as in the treatment of thyroid cancer, ${ }^{40}$ in chronic hepatitis B, ${ }^{41}$ and in HIV infection. ${ }^{42}$ Further studies should be performed to confirm whether $\mathrm{T}$ cell exhaustion occurs in L. amazonensis infection. However, other studies that have assessed how chronic infections can induce exhaustion, in addition to our results reporting the increased capacity of IFN- $\gamma$ 
production after MoAbs therapy, this suggests that $T$ cell exhaustion occurs in $L$. amazonensis infection.

Interestingly, our results indicate the MoAb potential to modulate the cytokines present at the lesion site in the mice, as the production of IL-4 and TGF- $\beta$ were reduced in the group treated with the anti-PD-1 MoAb. The group treated with antiPD-L1 MoAb showed a tendency in the reduction of TGF- $\beta$. It is already known that patients who progress to the disease have an increase in the production of IL-4 directed by a Th2 response and suppressor responses by the increase of TGF- $\beta$ ( $L$. chagasi) and IL-10 (L. donovani). ${ }^{43,44}$ In another study, TGF- $\beta$ was able to upregulate the PD-L1 expression in dendritic cells, leading to T-cell anergy and diminished antitumor response. ${ }^{45}$ In visceral leishmaniasis, it has been observed that patients who had progression of the disease showed increased IL-10 production, ${ }^{39}$ which was not seen in our results, since the concentration of IL-10 showed a slight reduction in the MoAb-treated groups relative to the PBS control. Thus, our data support the hypothesis that IFN- $\gamma$ produced by $C D 4^{+} T$ cells inhibits the development of a Th2 response by diminishing IL-4 and reducing TGF- $\beta$ production. Moreover, it is important to point out that TGF- $\beta$ is associated with increased parasite load ${ }^{46}$ and its reduction is directly related to parasite control. Hence, in our results, parasitic control may also be related to the decrease of TGF- $\beta$ and PD-L1 expression.

We also evaluated if the humoral response was altered during MoAb treatment. Kima et al. showed that antibodies play a critical role in the pathogenesis and in the development of more significant lesions due to $L$. amazonensis infection, since the maintenance of infection by these parasites was impaired by the absence of circulating antibodies in the BALB/c model. ${ }^{47}$ Recently, we demonstrated that $L$. amazonensis infection in XID mice displayed smaller lesions and a decrease in IL-10 and total antibodies in comparison to WT mice suggesting the pathogenic role of $B$ cells in $L$. amazonensis infection. ${ }^{48}$ Here, we demonstrated that treatment with both MoAbs did not affect the anti-Leishmania $\lg \mathrm{M}$ and $\lg \mathrm{G}$ antibodies levels.

In summary, our study suggests a potential use of monoclonal antibodies against PD-1 and PD-L1 in the treatment of cutaneous leishmaniasis caused by $L$. amazonensis. Our model, which employed a low dose treatment of anti-PD-1 or antiPD-L1 showed therapeutic efficacy to control the parasite load in infected mice. We have also shown that this control is related to $\mathrm{CD}^{+} \mathrm{T}$ lymphocytes and, partially, to $\mathrm{CD}^{+} \mathrm{T}$ lymphocytes, producing IFN- $\gamma$. These findings could potentiate a combined 
therapy using anti-PD-1 or anti-PD-L1 antibodies and the current standard therapies against leishmaniasis, which could be particularly important for diffuse cutaneous leishmaniasis treatment, a disease that is refractory to conventional treatment.

\section{ACKNOWLEDGEMENTS}

We would like to thank Bristol-Myers Squibb for the donation of anti-PD-L1, through the sharing of these technologies we can hopefully present a new cure for leishmaniasis. This work was supported by Fundação Carlos Chagas Filho de Amparo à Pesquisa do Estado do Rio de Janeiro (FAPERJ), Conselho Nacional de Desenvolvimento Científico e Tecnológico (CNPq), and Coordenação de Aperfeiçoamento de Pessoal de Nível Superior (CAPES), Finance Code 001.

\section{REFERENCES}

1. Ishida, Y. et al. "Induced expression of PD-1, a novel member of the immunoglobulin gene superfamily, upon programmed cell death." The EMBO journal vol. 11,11: 388795 (1992).

2. Torres-Guerrero, E. et al. "Leishmaniasis: a review." F1000Research vol. 6 750. 26 May doi:10.12688/f1000research.11120.1 (2017)

3. Dong, H., Zhu, G., Tamada, K. \& Chen, L. B7-H1, a third member of the B7 family, co-stimulates T-cell proliferation and interleukin-10 secretion. Nat Med.5: 1365-1369 (1999).

4. Nishimura, H. \& Honjo, T. PD-1: An inhibitory immunoreceptor involved in peripheral tolerance. Trends Immunol. 22: 265-268 (2001).

5. Wang, W., Lau, R., Yu, D., Zhu, W., et al. PD1 blockade reverses the suppression of melanoma antigen-specific $\mathrm{CTL}$ by $\mathrm{CD}^{+}{ }^{+} \mathrm{CD} 25(\mathrm{Hi})$ regulatory $\mathrm{T}$ cells. Int Immunol. 21:1065-1077 (2009).

6. Guerin, L.R., Prins, J.R., Robertson, S.A. Regulatory T-cells and immune tolerance in pregnancy: a new target for infertility treatment? Hum Reprod. Update. 15:517-535 (2009)

7. Iwai, Y., Ishida, M., Tanaka, Y., Okazaki, T., et al. Involvement of PD-L1 on tumor cells in the escape from host immune system and tumor immunotherapy by PD-L1 blockade. Proc Natl Acad Sci U S A. 99:12293-12297 (2002) 
8. Zou, W. \& Chen, L. Inhibitory B7-family molecules in the tumour microenvironment. Nat Rev Immunol. 8:467-477 (2008).

9. Curiel, T.J., Wei, S., Dong, H., et al. Blockade of B7-H1 improves myeloid dendritic cell-mediated antitumor immunity. Nat Med. 9:562-567 (2003).

10. Hino, R., Kabashima, K., Kato, Y., et al. Tumor cell expression of programmed cell death-1 ligand 1 is a prognostic factor for malignant melanoma. Cancer. 116:17571766 (2010).

11. Taube, J.M., Anders, R.A., Young, J.D., et al. Colocalization of inflammatory response with B7-H1 expression in human melanocytic lesions supports an adaptive resistance mechanism of immune escape. Sci Transl Med. 4 127ra37 (2012).

12. Patel, R., Bock, M., Polotti, C.F. \& Elsamra, S. Pharmacokinetic drug evaluation of atezolizumab for the treatment of locally advanced or metastatic urothelial carcinoma. Expert Opin Drug Metab Toxicol. 2017. Feb;13(2):225-232. doi: 10.1080/17425255.2017.1277204. Epub Jan 11 (2017).

13. Wang, C., Yu, X. \& Wang, W. A meta-analysis of efficacy and safety of antibodies targeting PD-1/PD-L1 in treatment of advanced nonsmall cell lung cancer. Medicine. 95(52), e5539 (2016).

14. Nikolova, M., Wiedemann, A., Muhtarova, M., et al. Subset- and Antigen-Specific Effects of Treg on CD8+ T Cell Responses in Chronic HIV Infection. PLoS Pathogens, 12(11), e1005995. http://doi.org/10.1371/journal. ppat.1005995 (2016).

15. Liang, S.C., Greenwald, R.J., Latchman, Y.E., et al. PD-L1 and PD-L2 have distinct roles in regulating host immunity to cutaneous leishmaniasis. Eur. J. Immunol. 36; 5864 (2006).

16. Latchman, Y., Wood, C.R., Chernova, T., et al. PD-L2 is a second ligand for PD-1 and inhibits T cell activation. Nat Immunol. 2: 261-268 (2001).

17. Zhang, Y., Chung, Y., Bishop, C., et al. Regulation of T cell activation and tolerance by PDL2. Proceedings of the National Academy of Sciences of the United States of America. 103(31),11695-11700. http://doi.org/10.1073/pnas.0601347103 (2006).

18. Bhadra, R., Gigley, J.P., Weiss, L.M. \& Khan, I.A. Control of Toxoplasma reactivation by rescue of dysfunctional CD8 ${ }^{+}$T-cell response via PD-1-PDL-1 blockade. Proc Natl Acad Sci U S A. 108:9196-9201 (2011).

19. Wherry, E.J. T cell exhaustion. Nat Immunol. 2011. 12:492-499 (2011). 
20. Hernandez-Ruiz, J., Salaiza-Suazo, N., Carrada, G., et al. CD8 cells of patients with diffuse cutaneous leishmaniasis display functional exhaustion: the latter is reversed, in vitro, by TLR2 agonists. PLoS Negl Trop Dis. 4:e871. (2010).

21. De Matos Guedes, H.L., Da Fonseca-Martins, A.M., Carlsen, E.D., et al. Leishmania amazonensis induces PD-L1 on Dendritic cells that impair Th1 response. Submited. (2019).

22. Scott, $P$. The role of Th1 and Th2 cells in experimental cutaneous leishmaniasis. Exp. Parasitol. 68(3): 369-372 (1989).

23. Heinzel, F.P., Sadick, M.D., Holaday, B.J., et al. Reciprocal expression of interferon gamma or interleukin 4 during the resolution or progression of murine leishmaniasis. Journal of Experimental Medicine. 169, 59-72 (1989).

24. Awasthi, A., Mathur, R.K. Saha, B. Immune response to Leishmania infection. Indian Journal of Medical Research. 119(6):238-258 (2004).

25. Qi, H., Ji, J., Wanasen, N. \& Soong, L. Enhanced replication of Leishmania amazonensis amastigotes in gamma interferon-stimulated murine macrophages: implications for the pathogenesis of cutaneous leishmaniasis. Infect Immun. 72: 988995 (2004).

26. Marin-Acevedo, J.A., Dholaria, B., Soyano, A.E., et al. Next generation of immune checkpoint therapy in cancer: new developments and challenges. Journal of hematology \& oncology. 11(1), 39. doi:10.1186/s13045-018-0582-8 (2018).

27. Topalian, S.L., Hodi, F.S., Brahmer, J.R., et al. Safety, activity, and immune correlates of anti-PD-1 antibody in cancer. N Engl J Med. 366: 2443-2454 (2012).

28. Brahmer, J.R., Tykodi, S.S., Chow, L.Q., et al. Safety and activity of anti-PD-L1 antibody in patients with advanced cancer. N Engl J Med. 366: 2455-2465 (2012).

29. Mou, Z., Muleme, H.M., Liu, D., et al. Parasite-derived arginase influences secondary anti-Leishmania immunity by regulating programmed cell death-1-mediated CD4+ ${ }^{+}$cell exhaustion. J Immunol. 190:3380-3389 (2013).

30. Esch, K.J., Juelsgaard, R., Martinez, P.A., et al. PD-1-mediated T cell exhaustion during visceral leishmaniasis impairs phagocyte function. Journal of Immunology. (Baltimore, Md.:1950), 191(11),5542-5550. http://doi.org/10.4049/jimmunol.1 301810 (2013).

31. Habib, S., El Andaloussi, A., Elmasry, K., et al. PDL-1 Blockade Prevents T Cell Exhaustion, Inhibits Autophagy, and Promotes Clearance of Leishmania donovani. Infection and immunity. 86(6),e00019-18.doi:10.1128/IA I.00019-18 (2018). 
32. Barroso, D.H., Falcão, S.A.C., Motta, J.O.C., et al. PD-L1 May Mediate T-Cell Exhaustion in a Case of Early Diffuse Leishmaniasis Caused by Leishmania (L.) amazonensis. Front. Immunol. 11 May https://.org/10.3389/fimmu.20 18.01021 (2018).

33. Shindo, Y., Yoshimura, K., Kuramasu, A., et al. Combination immunotherapy with 4-1BB activation and PD-1 blockade enhances antitumor efficacy in a mouse model of subcutaneous tumor. Anticancer Res. Jan;35(1):129-36 (2015).

34. Blake, S.J.P., Ching, A.L.H., Kenna, T.J., et al. Blockade of PD-1/PD-L1 Promotes Adoptive T-Cell Immunotherapy in a Tolerogenic Environment. Labrecque N, ed. PLoS ONE. 10(3):e0119483. doi:10.1371/journal.pone.0119483 (2015).

35. Soares, K.C., Rucki, A.A., Wu, A.A., et al. PD-1/PD-L1 blockade together with vaccine therapy facilitates effector $T$ cell infiltration into pancreatic tumors. Journal of immunotherapy. (Hagerstown, Md: 1997). 38(1):1-11. Doi:10.1097/CJI.0000000000 000062 (2015).

36. Joshi, T., Rodriguez, S., Perovic, V., et al. B7-H1 blockade increases survival of dysfunctional CD8(+) T cells and confers protection against Leishmania donovani infections. PLoS Pathog. May;5(5):e1000431. doi:10.1371/journal.ppat.1000431. Epub May 15 (2009).

37. Afonso, L.C. \& Scott, P. Immune response associated with susceptibility of C57BL/10 mice to Leishmania amazonensis. Infect Immun. 61: 2952-2959 (1993).

38. Soong, L., Chang, Ch., Sun, J., et al. Role of $\mathrm{CD}^{+} \mathrm{T}$ cells in pathogenesis associated with Leishmania amazonensis infection. J Immunol. 158:5374-5383 (1997).

39. Boggiatto, P.M., Ramer-Tait, A.E., Metz, K., et al. Immunologic indicators of clinical progression during canine Leishmania infantum infection. Clin Vaccine Immunol. 17:267-273 (2010).

40. Bastman, J.J., Serracino, H.S., Zhu, Y., et al. Tumor-infiltrating T Cells and the PD-1 checkpoint pathway in advanced differentiated and anaplastic thyroid cancer. Journal of Clinical Endocrinology \& Metabolism. 1012863-2873. doi:10.1210/ jc.20154227 (2016).

41. Nebbia, G., Peppa, D., Schurich, A., et al. Upregulation of the Tim-3/galectin- 9 pathway of $\mathrm{T}$ cell exhaustion in chronic hepatitis $\mathrm{B}$ virus infection. PLoS ONE. 7(10):e47648. doi:10.1371/journal.pone.004 7648 (2012).

42. Trautmann, L., Janbazian, L., Chomont, N. et al. Upregulation of PD-1 expression on HIV-specific CD8 ${ }^{+} \mathrm{T}$ cells leads to reversible immune dysfunction. Nat Med. 12(10):1198-1202 (2006). 
43. Nylen, S., Maurya, R., Eidsmo, L., Manandhar, K.D., et al. Splenic accumulation of IL-10 mRNA in T cells distinct from CD4+CD25+ (Foxp3) regulatory T cells in human visceral leishmaniasis. J Exp Med. 204:805-817 (2007).

44. Wilson, M.E., Recker, T.J., Rodriguez, N.E., et al. The TGF-beta response to Leishmania chagasi in the absence of IL-12. Eur J Immunol. 32:3556-3565 (2002).

45. Song, S., Yuan, P., Wulingyu, H., et al. Dendritic cells with an increased PD-L1 by TGF- $\beta$ induce $T$ cell anergy for the cytotoxicity of hepatocellular carcinoma cells. International Immunopharmacology. Vol. 20, Issue 1, May 2014, Pages 117-123. https://doi.org/10.1016/j.intimp.2014.02.027 (2014).

46. Pinheiro, R.O., Pinto, E.F., Lopes, J.R., et al. TGF-beta-associated enhanced susceptibility to leishmaniasis following intramuscular vaccination of mice with Leishmania amazonensis antigens. Microbes Infect. Oct;7(13):1317-23. Epub Jun 13. PubMed PMID: 16027022 (2005).

47. Kima, P.E., Constant, S.L., Hannum, L., et al. Internalization of Leishmania mexicana complex amastigotes via the $\mathrm{Fc}$ receptor is required to sustain infection in murine cutaneous leishmaniasis. Journal of Experimental Medicine. 191, pp. 10631067 (2000).

48. Firmino-Cruz, L., Ramos, T.D., Da Fonseca-Martins, A.M., Maciel-Oliveira, D., et al. Immunomodulating role of IL-10-producing B cells in Leishmania amazonensis infection. Cell Immunol. Aug 22. pii:S0008-8749(18)30261-2. doi:10.1016/j. cellimm.2018.08.014 (2018). 


\section{FIGURE LEGENDS}

Fig. 1: Expression of PD-1 on $\mathrm{CD}^{+}$and $\mathrm{CD} 8^{+} \mathrm{T}$ cells in $\mathrm{L}$. amazonensis-infected BALB/c mice. Lymphocytes from the macerated draining popliteal lymph node of an L. amazonensis-infected paw were collected at 56 days post-infection. Uninfected mice were used as control. $\mathbf{a}-\mathbf{b}$ Percentage and absolute number of PD- $1^{+} \mathrm{CD} 4^{+} \mathrm{T}$ cells and PD- $1^{+} \mathrm{CD} 8^{+} \mathrm{T}$ cells. c Dot plots showing PD-1 expression (PE-Cy7-PD-1 ${ }^{+}, \mathrm{FSC}-$ cell volume). ${ }^{*} \mathrm{p}<0.05,{ }^{* *} \mathrm{p}<0.0375$ ( $\mathrm{T}$ Test). The data show means \pm standard deviations; $n=8-13$.

Fig. 2: Lesion development and parasite load in L. amazonensis-infected BALB/c mice. Mice were infected with L. amazonensis promastigotes $\left(2 \times 10^{6}\right)$ and treated with either anti-PD-1 or anti-PD-L1 MoAbs (100 $\mu \mathrm{g} / \mathrm{dose})$, administered twice a week intraperitoneally, beginning at 7 days post-infection, for 56 days. a Lesion size. b Parasite load. ${ }^{*} \mathrm{p}<0.05,{ }^{* * *} \mathrm{p}<0.0001$ (t-test). The data (means \pm standard deviations; $n=5$ ) are representative of two independent experiments producing the same result profile.

Fig. 3: Effect of anti-PD-1 and anti-PD-L1 MoAbs on the percentage and number of IFN $-\boldsymbol{\gamma}^{+} \mathrm{CD8}^{+} \mathbf{T}$ cells. Lymphocytes were collected from the draining lymph node of an L. amazonensis-infected paw after 56 days of treatment with anti-PD-1 or anti-PDL1, administered twice a week intraperitoneally beginning 7 days after infection. a Percentage of $\mathrm{CD}^{+} \mathrm{CD} 8^{+} \mathrm{T}$ cells. $\mathbf{b}$ Number of $\mathrm{CD} 3^{+} \mathrm{CD} 8^{+} \mathrm{T}$ cells. $\mathbf{c}$ Dot plots showing IFN-y expression (APC-IFN- $\gamma$, FSC-cell volume). d Percentage of IFN- $\gamma^{+}$CD8 ${ }^{+} \mathrm{T}$ cells. e Number of IFN $-\gamma^{+} \mathrm{CD} 8{ }^{+}$T cells. ${ }^{*} p<0.05,{ }^{* *} p<0.0001$, (T Test (d), ANOVA (e)). Naive $=$ mice without infection and therapy, PBS = infected mice injected with PBS on treatment days, PD-1 = mice infected and treated with anti-PD-1 (100 $\mu \mathrm{g} /$ dose), PD$\mathrm{L} 1=$ mice infected and treated with anti-PD-L1 (100 $\mu \mathrm{g} /$ dose). Data (means \pm standard deviations; $n=5$ ) are representative of three independent experiments producing the same result profile. 
Fig. 4: Increase of IFN- $\gamma^{+} \mathrm{CD}^{+} \mathrm{T}$ cells after anti-PD-1 and anti-PD-L1 MoAb treatment. Lymphocytes were collected from the popliteal lymph node of an $L$. amazonensis-infected paw after approximately 2 months of treatment with anti-PD-1 or anti-PD-L1, administered twice a week intraperitoneally beginning 7 days after infection. a Dot plot IFN- $\gamma$ and PD-1 expression (APC-IFN- $\gamma$, PE-Cy7-PD-1). b Percentage of IFN- $\gamma^{+} \mathrm{PD}-1^{-} \mathrm{CD} 8^{+} \mathrm{T}$ cells. c Number of IFN- $\gamma^{+} \mathrm{PD}-1^{-} \mathrm{CD} 8^{+} \mathrm{T}$ cells. $\mathbf{d}$ Percentage of IFN- $\gamma^{-}$PD $-1^{+} \mathrm{CD} 8^{+} \mathrm{T}$ cells. e Number of IFN- $\gamma^{-} \mathrm{PD}-1^{+} \mathrm{CD} 8^{+} \mathrm{T}$ cells. $\mathbf{f}$ Percentage of IFN $-\gamma^{+} \mathrm{PD}-1^{+} \mathrm{CD} 8^{+} \mathrm{T}$ cells. $\mathbf{g}$ Number of IFN $-\gamma^{+} \mathrm{PD}-1^{+} \mathrm{CD} 8^{+} \mathrm{T}$ cells. ${ }^{*} \mathrm{p}$ <0.05, (T Test). Naive= mice without infection and therapy, PBS = infected mice injected with PBS on treatment days, PD-1 = mice infected and treated with anti-PD1 (100 $\mu \mathrm{g} /$ dose), PD-L1= mice infected and treated with anti-PD-L1 (100 $\mu \mathrm{g} / \mathrm{dose})$. The data (means \pm standard deviations; $n=5$ ) are representative of three independent experiments producing the same result profile.

Fig. 5: Increase of IFN- $\gamma^{+} \mathrm{CD4}^{+} \mathrm{T}$ cells after anti-PD-1 and anti-PD-L1 MoAb treatment. Lymphocytes were collected from the popliteal lymph node of an $L$. amazonensis-infected paw after approximately 2 months of treatment with anti-PD-1 or anti-PD-L1, administered twice a week intraperitoneally beginning after 7 days of infection. a Percentage of $\mathrm{CD} 3^{+} \mathrm{CD} 4^{+} \mathrm{T}$ cells. $\mathbf{b}$ Number of $\mathrm{CD} 3^{+} \mathrm{CD} 4^{+} \mathrm{T}$ cells. $\mathbf{c}$ Dot plot of IFN-y expression (APC-IFN- $\gamma$, FSC-cell volume). d Percentage of IFN- $\gamma^{+}$CD4 ${ }^{+}$ T cells. (E) Number of IFN- $\boldsymbol{r}^{+} \mathrm{CD} 4^{+} \mathrm{T}$ cells. ${ }^{*} \mathrm{p}<0.05,{ }^{* *} \mathrm{p}<0.0375$ (T Test (d) and ANOVA (e)). Naive $=$ mice without infection and therapy, PBS $=$ infected mice injected with PBS on treatment days, PD-1 = mice infected and treated with anti-PD-1 (100 $\mu \mathrm{g} /$ dose $),$ PD-L1 = mice infected and treated with anti-PD-L1 (100 $\mu \mathrm{g} / \mathrm{dose})$. The data (means \pm standard deviations; $n=5$ ) are representative of three independent experiments producing the same result profile. 
Fig. 6: Increase in the percentage of IFN $-\gamma^{+}$PD $-1^{+}$CD4 ${ }^{+} \mathrm{T}$ cells after anti-PD-1 and anti-PD-L1 MoAb treatment. Lymphocytes were collected from the popliteal lymph node of an $L$. amazonensis-infected paw after approximately 2 months of treatment with anti-PD-1 or anti-PD-L1, administered twice a week intraperitoneally beginning after 7 days of infection. a Dot plot of IFN-y and PD-1 expression (APC-IFN- $\gamma$, PECy7-PD-1). b Percentage of IFN- $\gamma^{+}$PD-1-CD4 ${ }^{+}$T cells. $\mathbf{c}$ Number of IFN- $\gamma^{+}$PD-1-CD4 ${ }^{+}$ T cells. $\mathbf{d}$ Percentage of IFN- $\gamma^{-P D}-1^{+} \mathrm{CD} 4^{+} \mathrm{T}$ cells. e Number of IFN- $\gamma^{-P D}-1^{+} \mathrm{CD} 4^{+} \mathrm{T}$ cells. $f$ Percentage of IFN $-\gamma^{+} P D-1{ }^{+} C D 4^{+} T$ cells. $g$ Number of IFN- $\gamma^{+} P D-1^{+} \mathrm{CD} 4^{+} \mathrm{T}$ cells. ${ }^{*} p<0.05$ (T Test (d) and ANOVA (f)). Naive = mice without infection and therapy, PBS = infected mice injected with PBS on treatment days, PD-1= mice infected and treated with anti-PD-1 (100 $\mu \mathrm{g} /$ dose), PD-L1= mice infected and treated with anti-PD$\mathrm{L} 1(100 \mu \mathrm{g} / \mathrm{dose})$. The data (means \pm standard deviations; $n=5)$ are representative of three independent experiments producing the same result profile.

Fig. 7: Selective reduction of IL-4 and TGF- $\beta$ in MoAb-treated groups. $L$. amazonensis-infected paws were collected and macerated after approximately 2 months of treatment with anti-PD-1 or anti-PD-L1, administered intraperitoneally twice a week beginning after 7 days of infection, and the supernatant was analyzed by ELISA: a IL-4, b TGF- $\beta$, c IL-10. ${ }^{*} p<0.05,{ }^{* *} \mathrm{p}<0.0375$ (ANOVA). The data (means \pm standard deviations; $n=5$ ) are representative of two independent experiments producing the same result profile. 


\section{SUPPLEMENTAL FIGURES}

Suppl. Fig. 1: Ineffectiveness of treatment with a weekly dose of specific antibodies. Mice were infected in the footpad with $L$. amazonensis promastigotes $\left(2 \times 10^{6}\right)$ and treated with anti-PD-1, anti-PD-L1 or anti-PD-L2, all at a $100 \mu \mathrm{g} / \mathrm{dose}$, administered once a week intraperitoneally beginning at 7 days post-infection. (A) Progression of the lesion. (B) Parasite load. The data (means \pm standard deviations; $n=5)$ are representative of an experiments.

Suppl. Fig. 2: Unaltered lesion growth and control of parasite load from two weekly doses of specific antibodies. Mice were infected in the footpad with $L$. amazonensis promastigotes $\left(2 \times 10^{6}\right)$ and treated with anti-PD-1, anti-PD-L1 or antiPD-L2, all at a $100 \mu \mathrm{g} /$ dose, administered twice per week intraperitoneally beginning at 7 days post-infection. (A) Progression of the lesion. (B) Parasite load of paw analyzed by limiting dilution. ${ }^{* * *} p<0.0001$ ( $T$ Test). The data (means \pm standard deviations; $n=5$ ) are representative of an experiment.

Suppl. Fig. 3: Treg cells in L. amazonensis-infected BALB/c mice. Mice were infected in the footpad with $L$. amazonensis promastigotes $\left(2 \times 10^{6}\right)$ and treated with anti-PD-1, anti-PD-L1 or anti-PD-L2, all at a $100 \mu \mathrm{g} /$ dose administered twice per week intraperitoneally beginning at 7 days post-infection. Naive mice were used as control. Percentage of Treg cells. The data (means \pm standard deviations; $n=5$ ) are representative of two independent experiments producing the same result profile.

\section{Suppl. Fig. 4: Effects of MoAb treatment on the specific anti-Leishmania} immunoglobulins. (A) Specific $\operatorname{lgM}$ and (B) IgG antibodies were detected in the serum (diluted 1:500) of $L$. amazonensis-infected mice through ELISA using total $L$. amazonensis antigens ( $1 \mu \mathrm{g} /$ well). Animals were treated for 49 days with antibodies administered twice a week intraperitoneally, starting at 7 days post-infection. Data (means \pm standard deviations; $n=5$ ) are representative of two independent experiments producing the same result profile. 


\section{Figure 1}
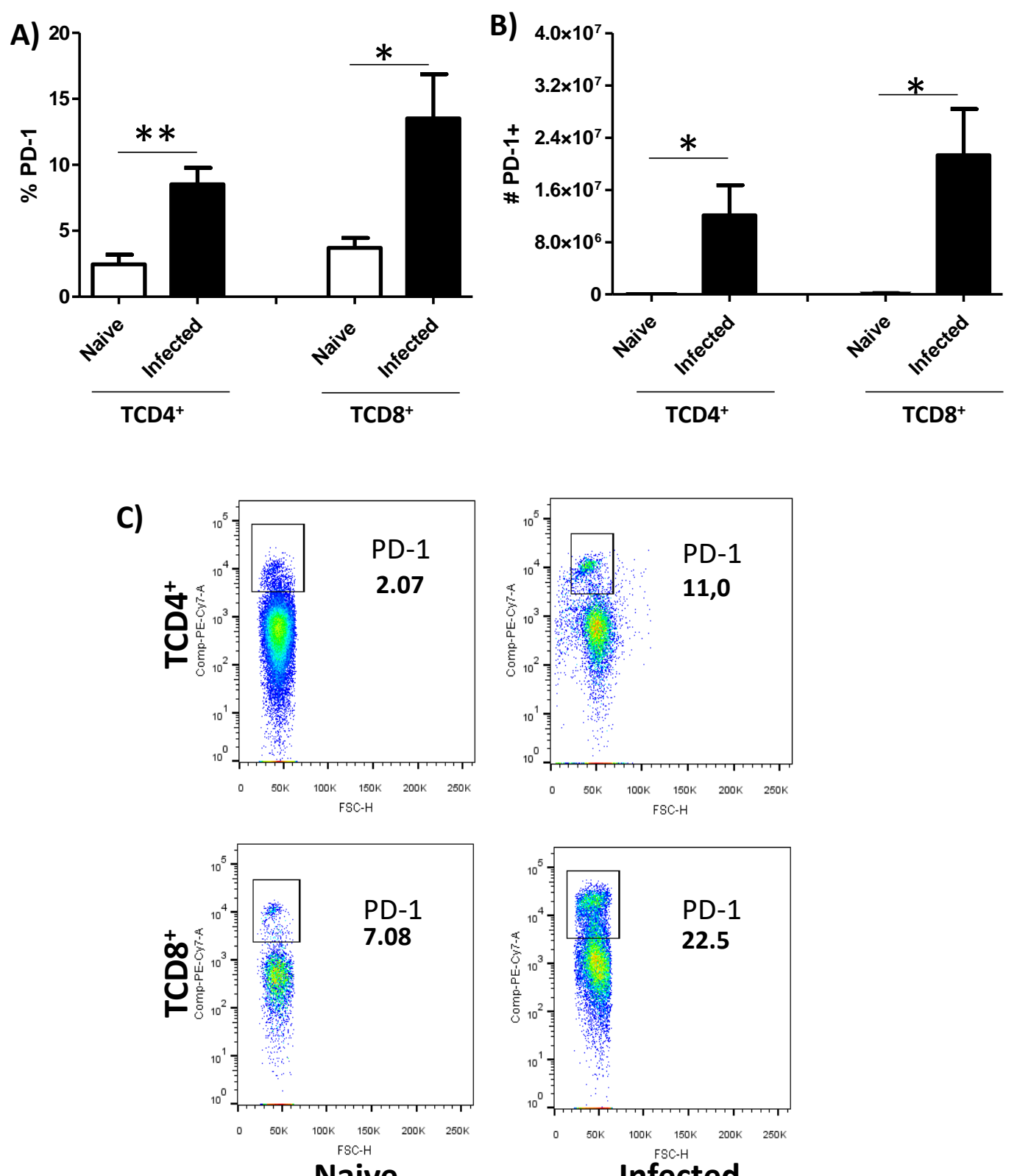

Naive

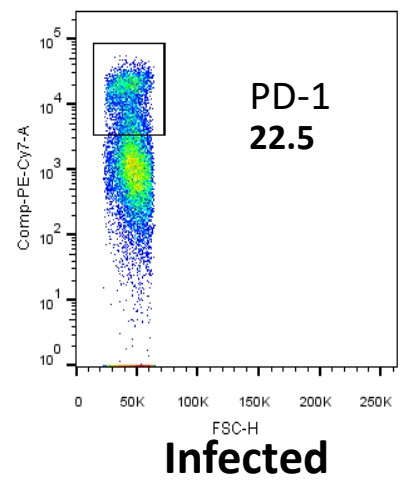


Figure 2

A)

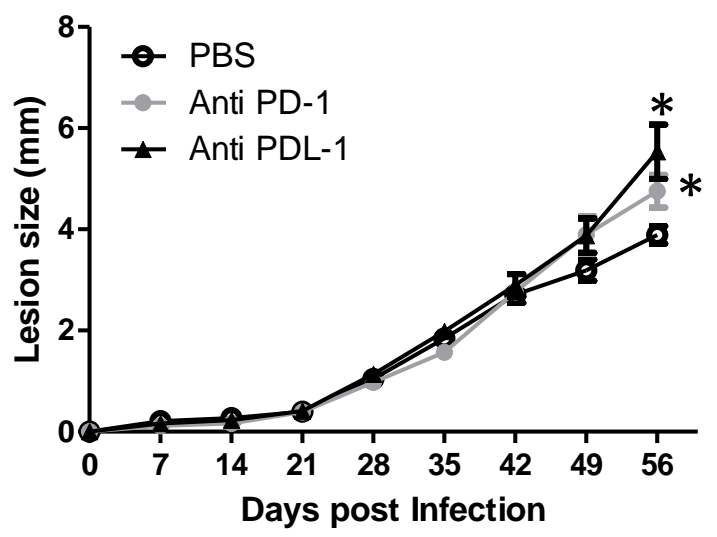

B)

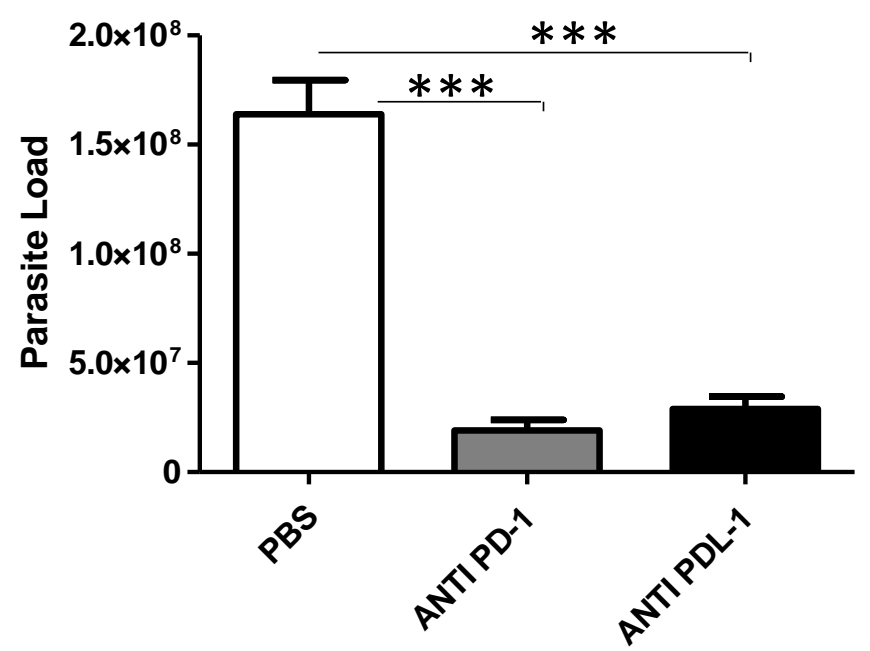




\section{Figure 3}

A)
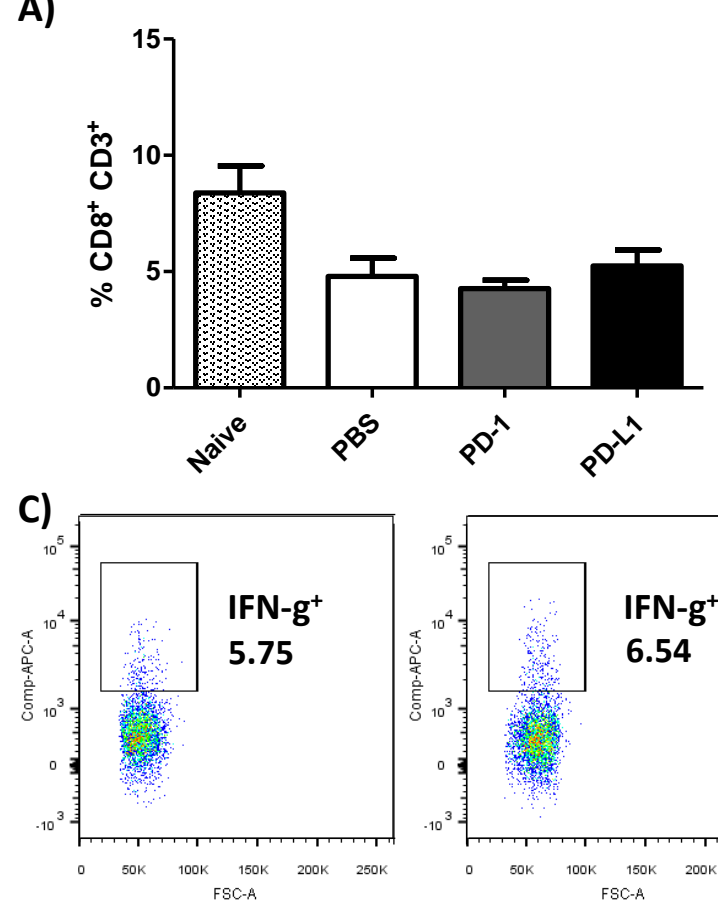

Naive

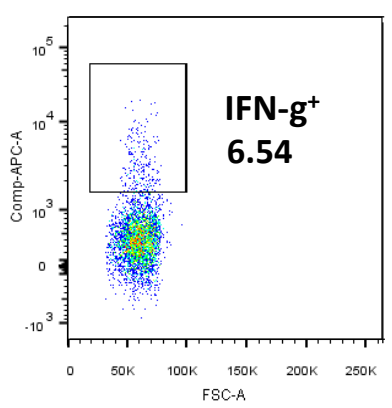

PBS

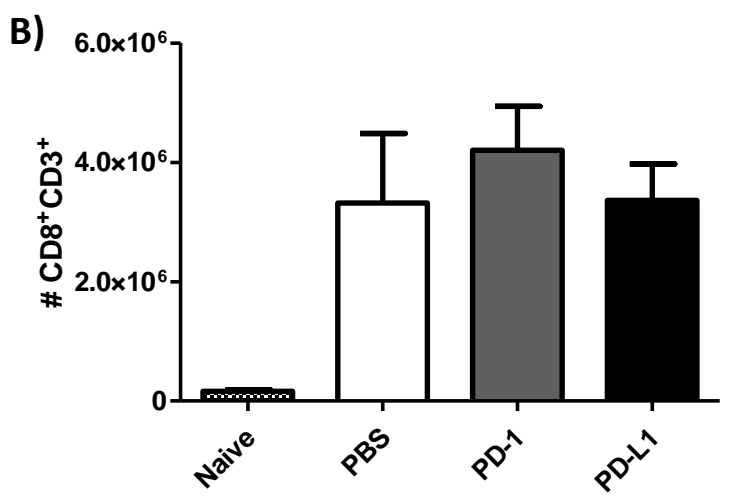

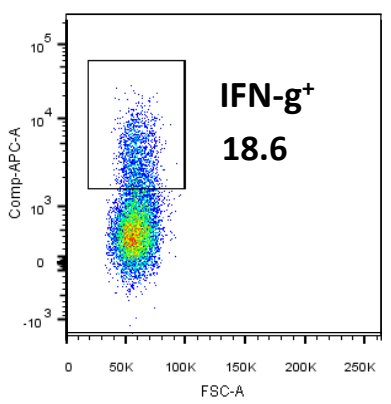

PD-1

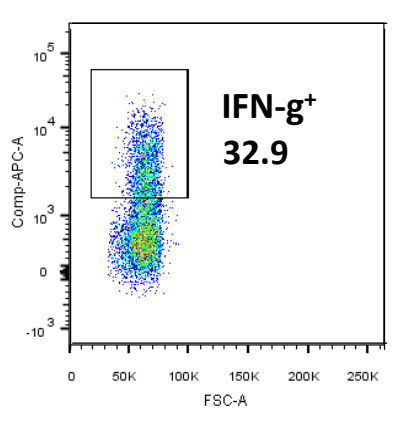

PD-L1
D)

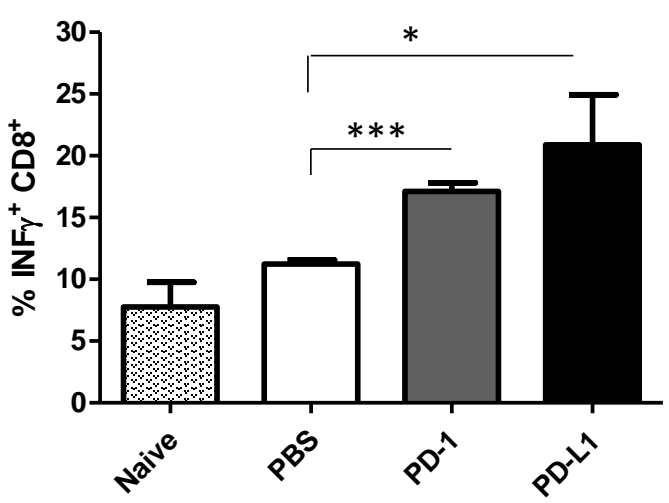

E)

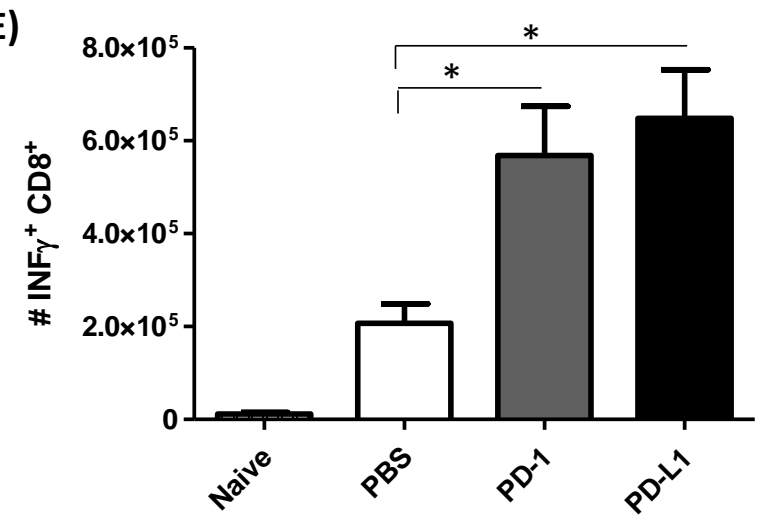


Figure 4

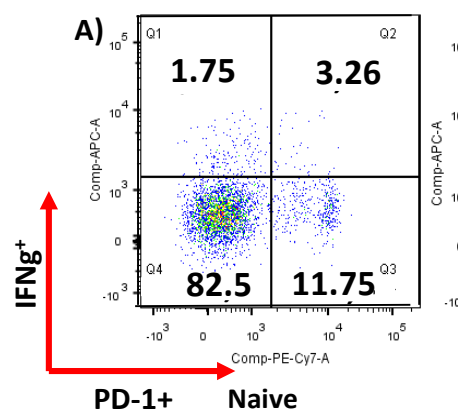

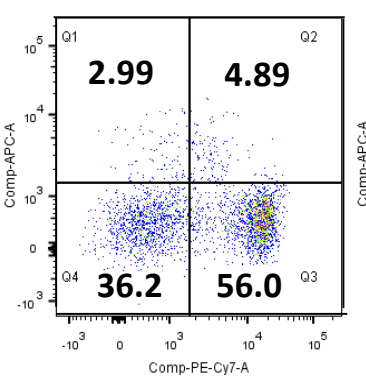

PBS

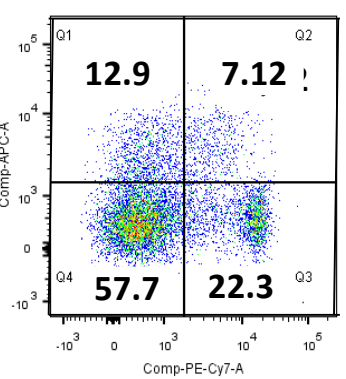

PD-1

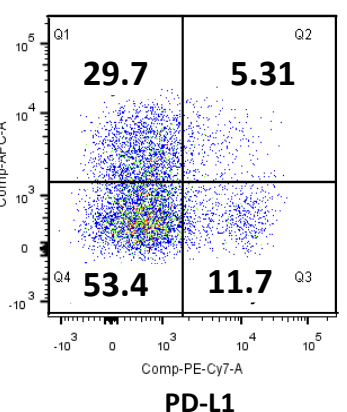

PD-L1
B)

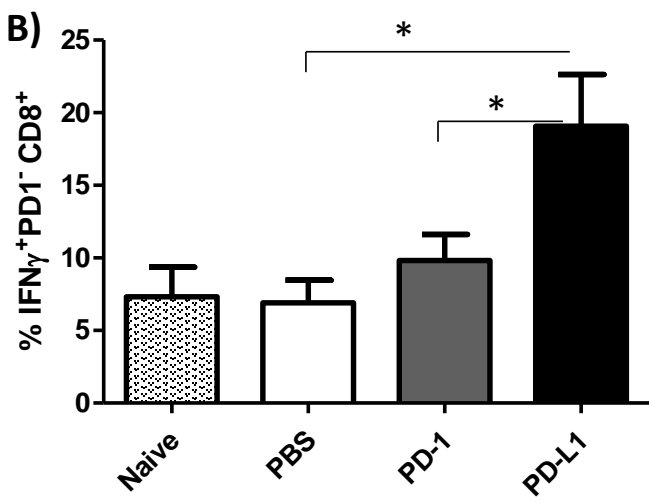

D)

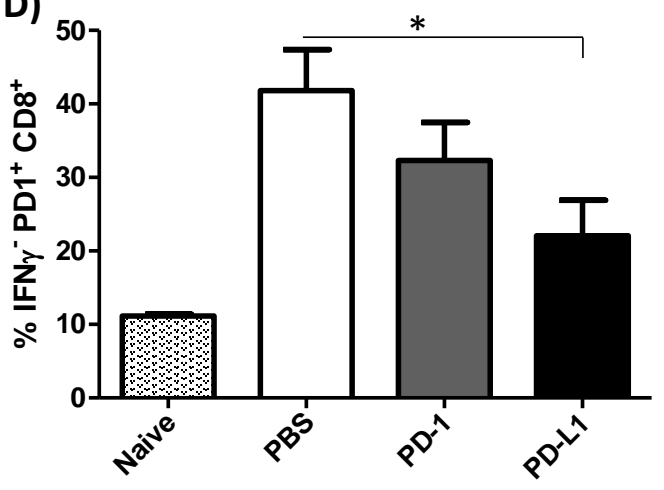

F)

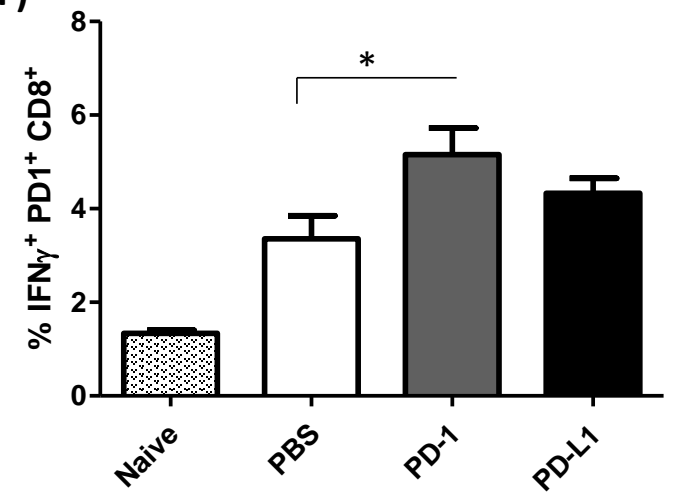

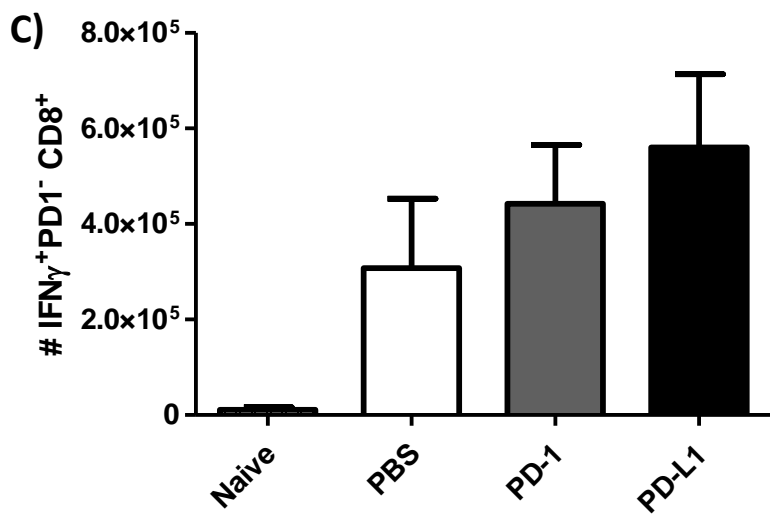

E)

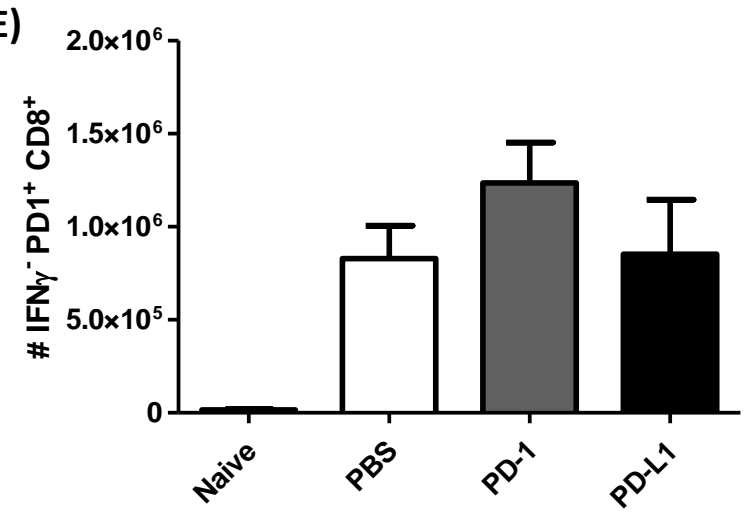

G)

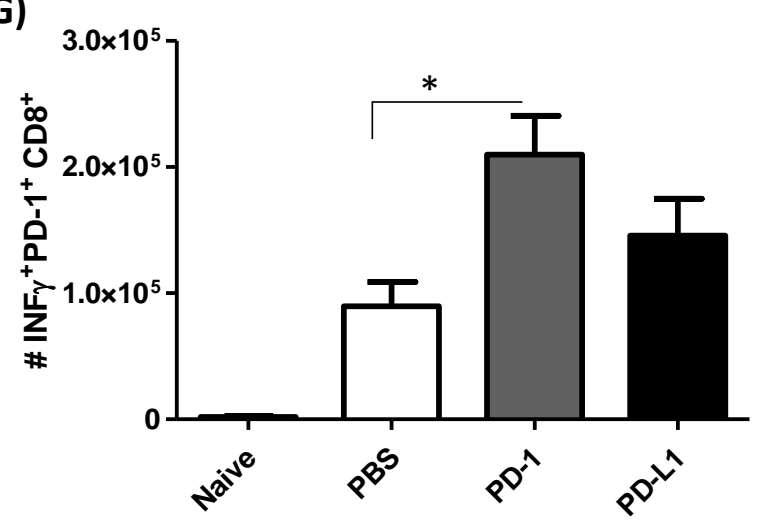


Figure 5

A)

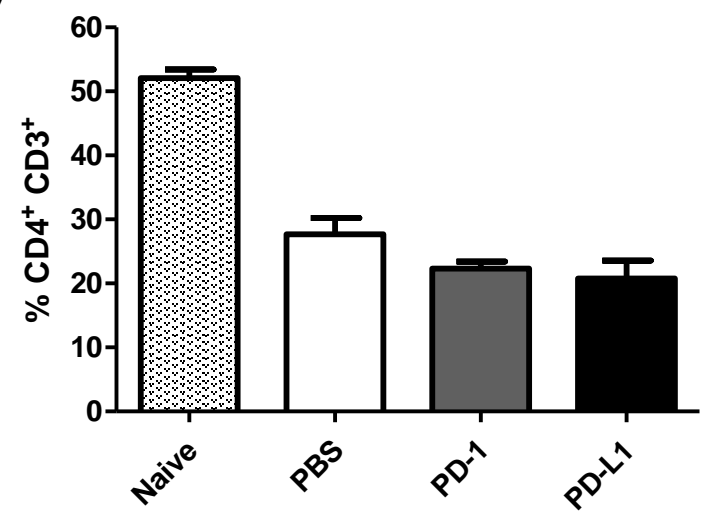

C)

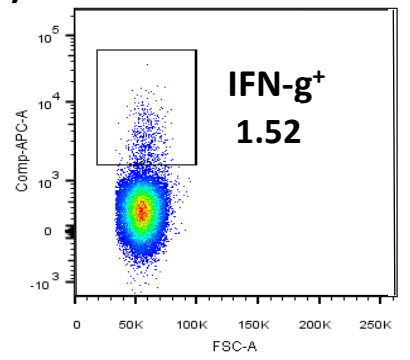

Naive

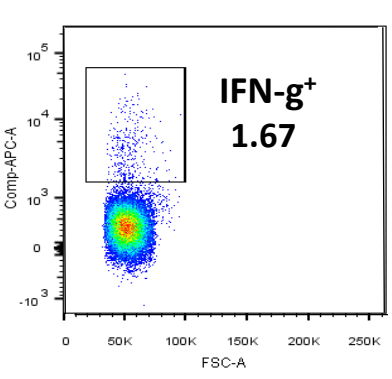

PBS
B)

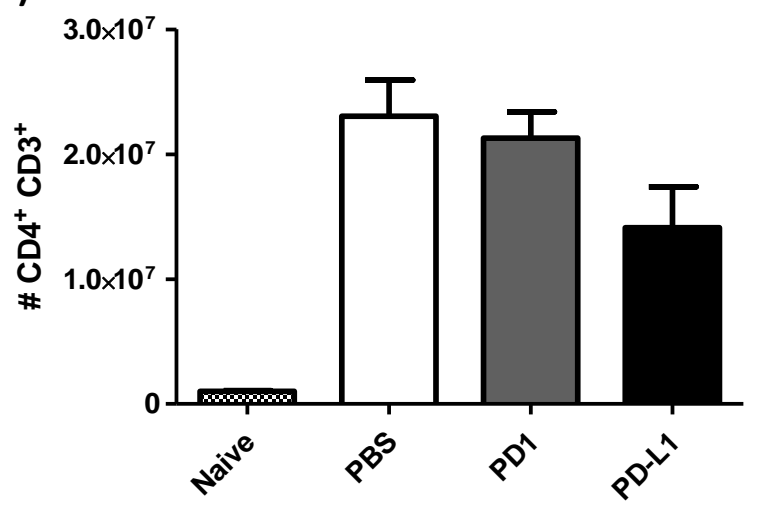

D)

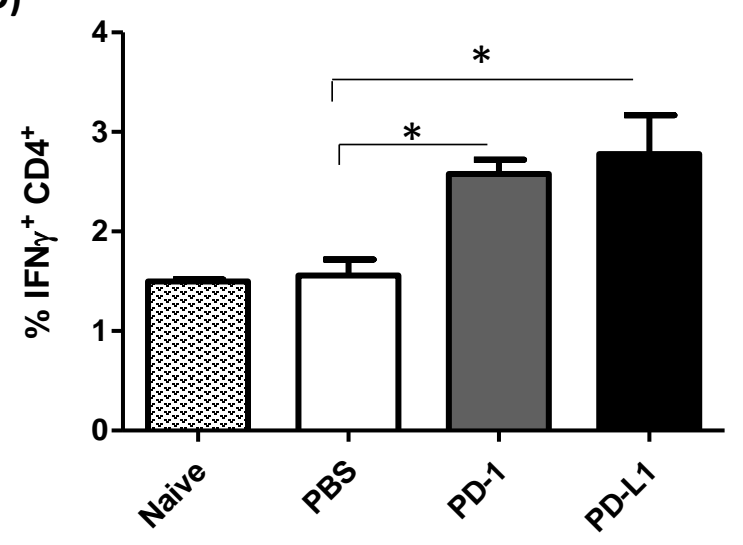

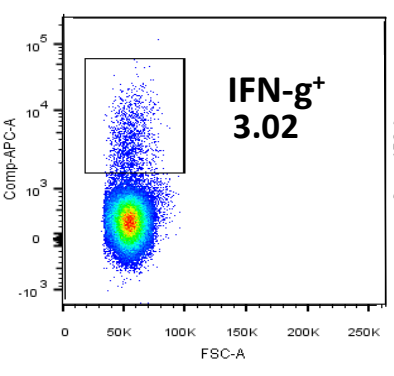

PD-1

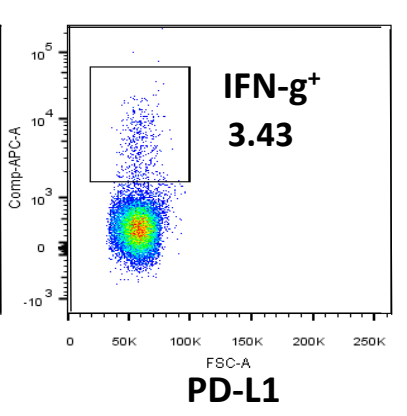

E)

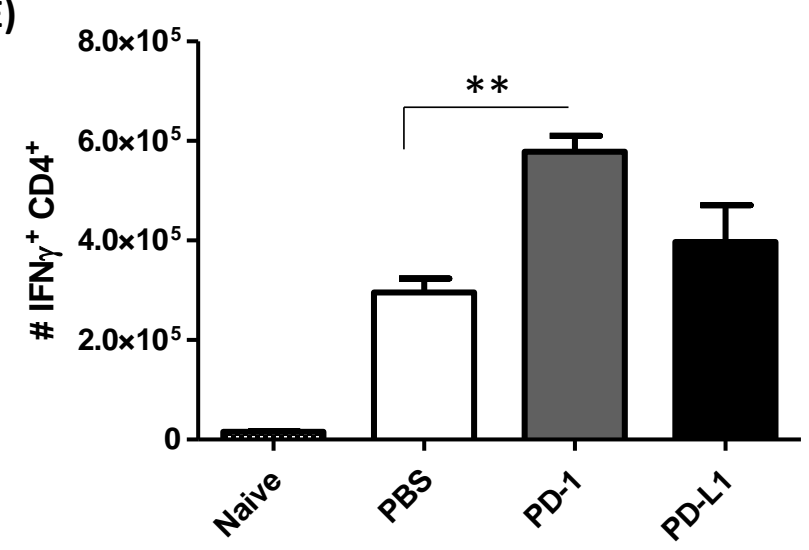


Figure 6

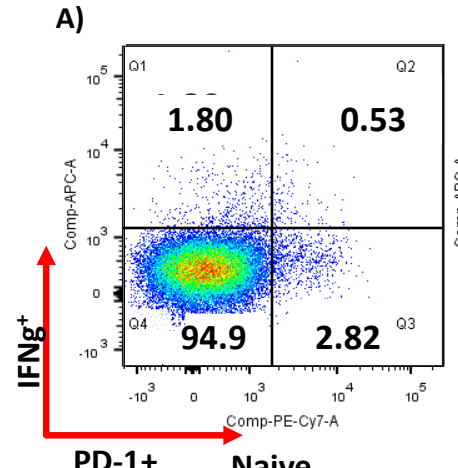

PD-1+ Naive

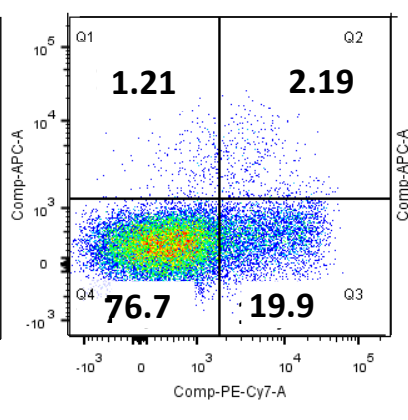

PBS

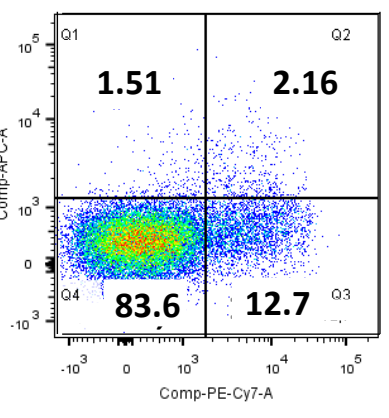

PD-1

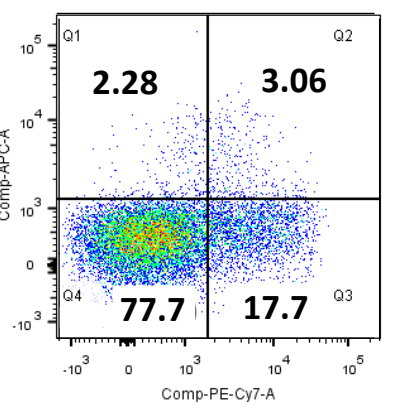

PD-L1
B)

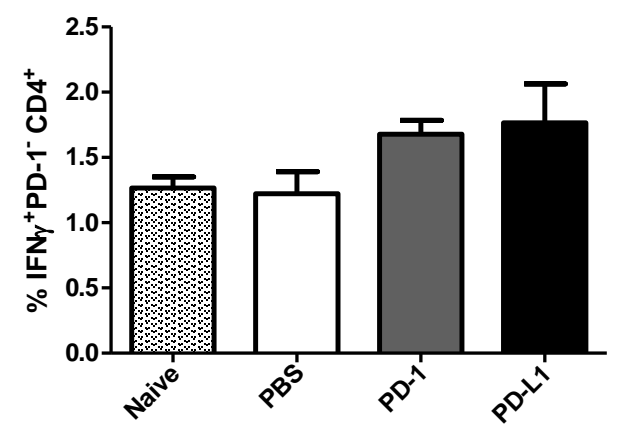

D)

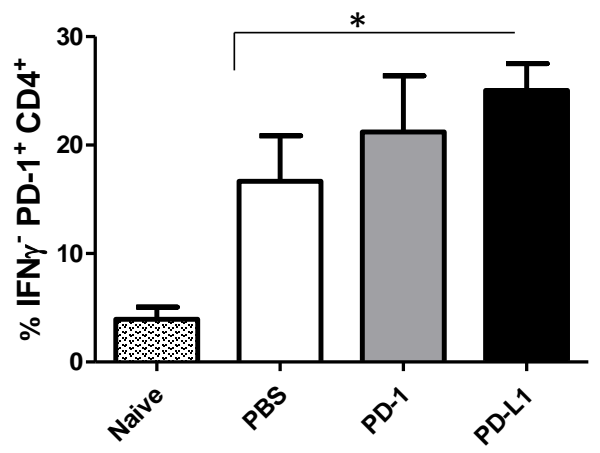

F)

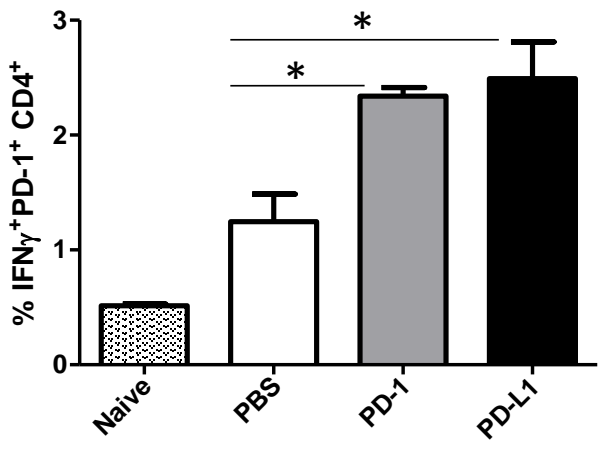

C)

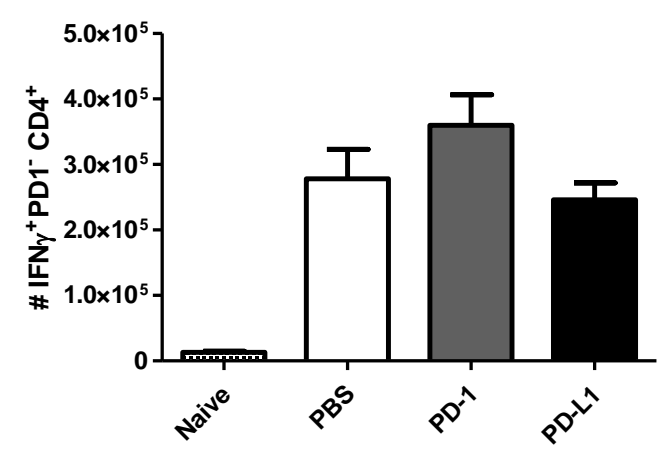

E)

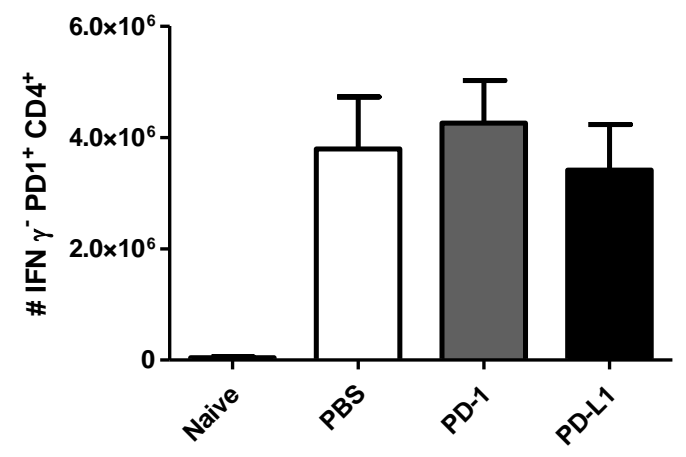

G)

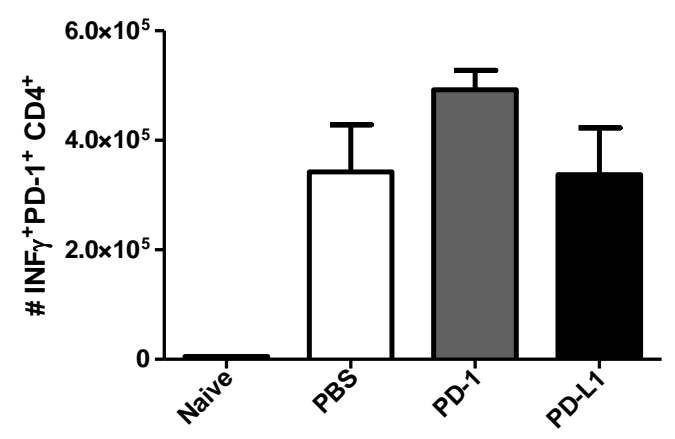


Figure 7

A)

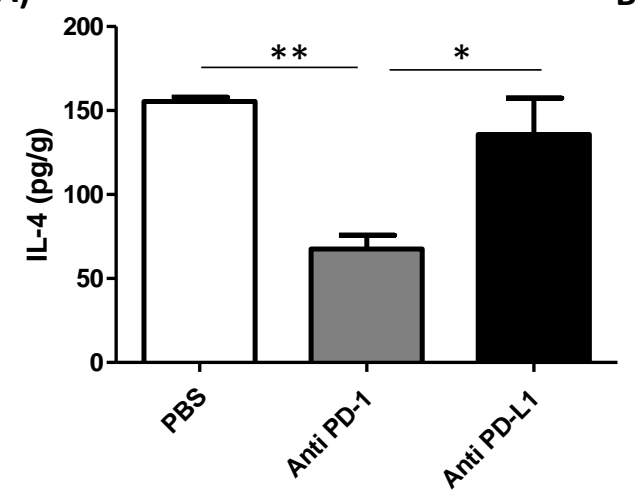

B)

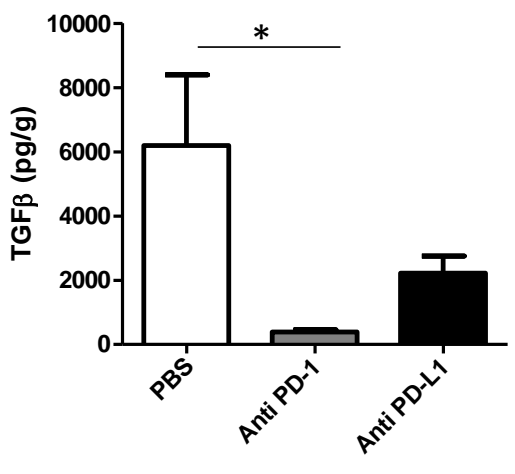

C)

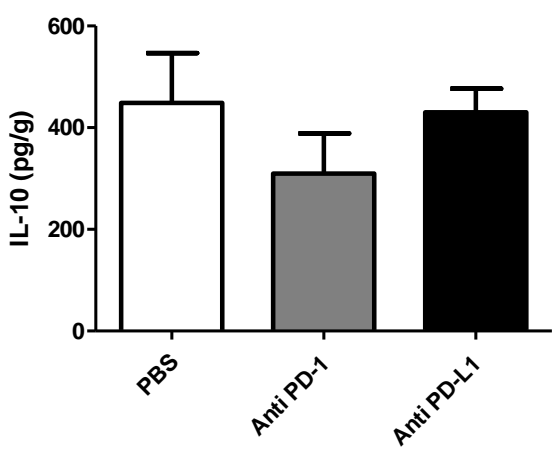



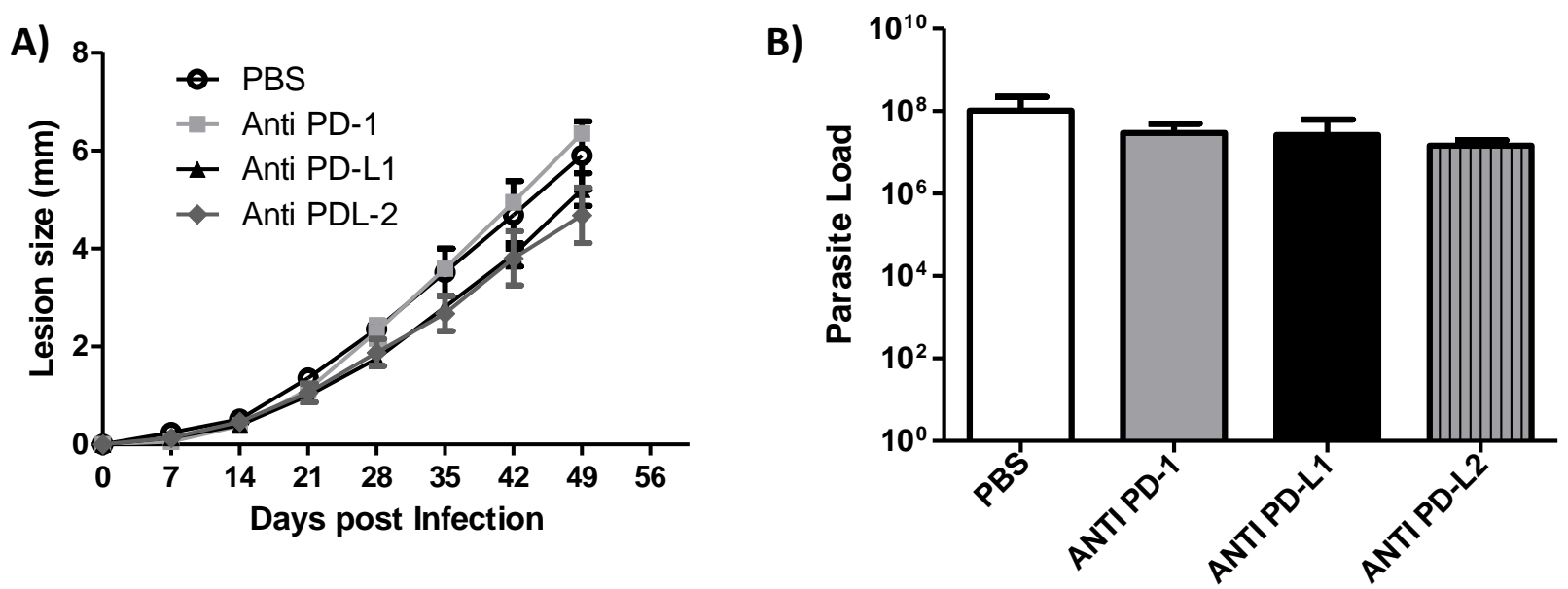


\section{Supplemental Figure 2}

A)

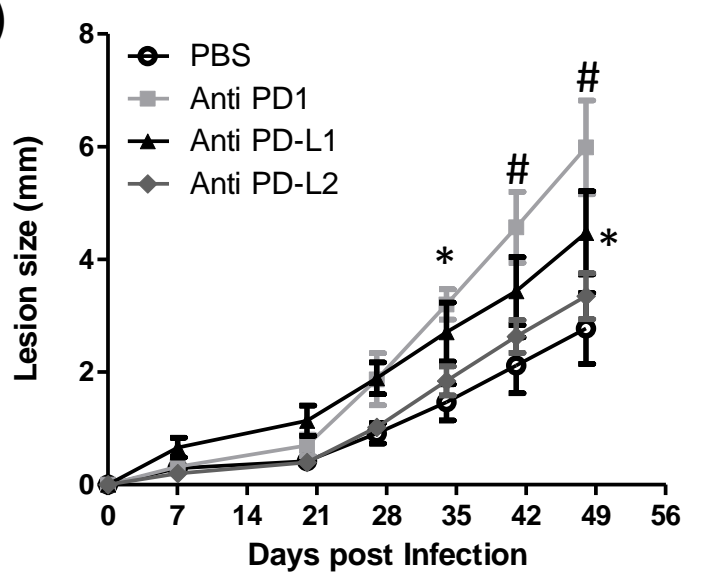

B)

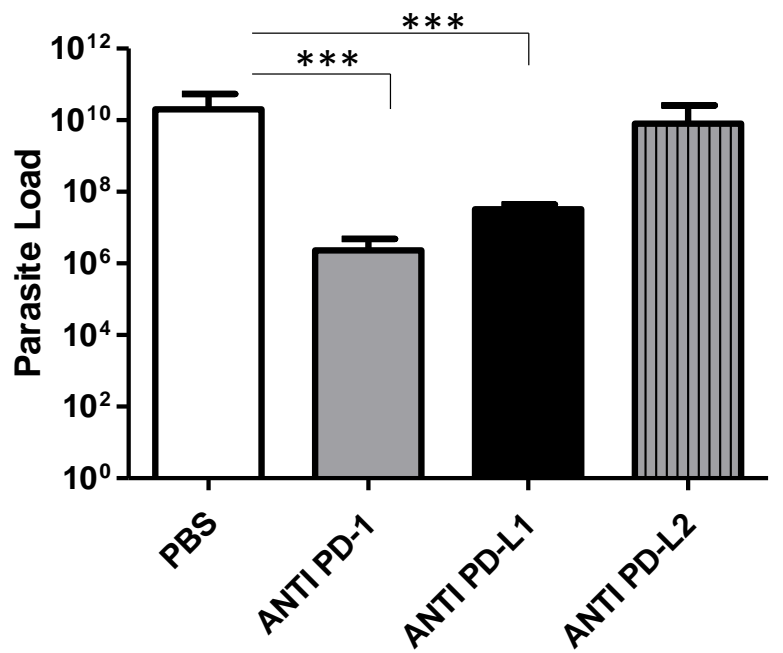


Supplemental Figure 3

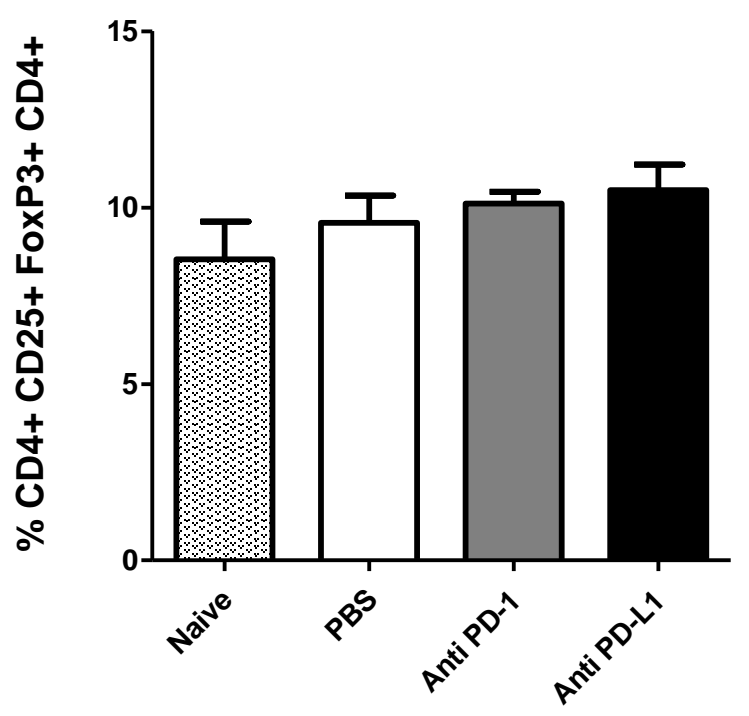




\section{Supplemental Figure 4}

A)

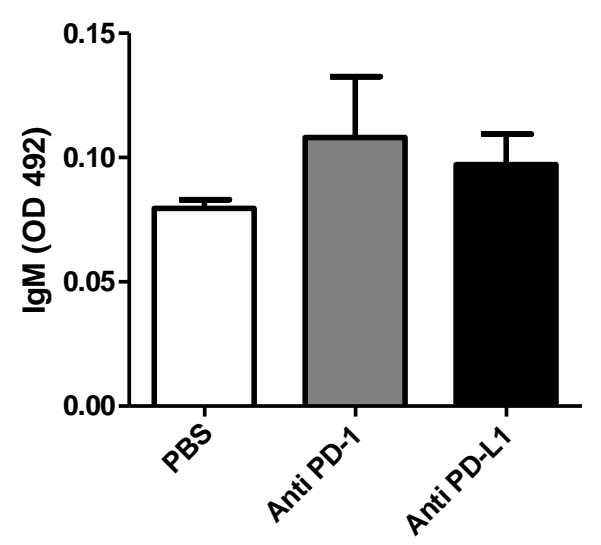

B)

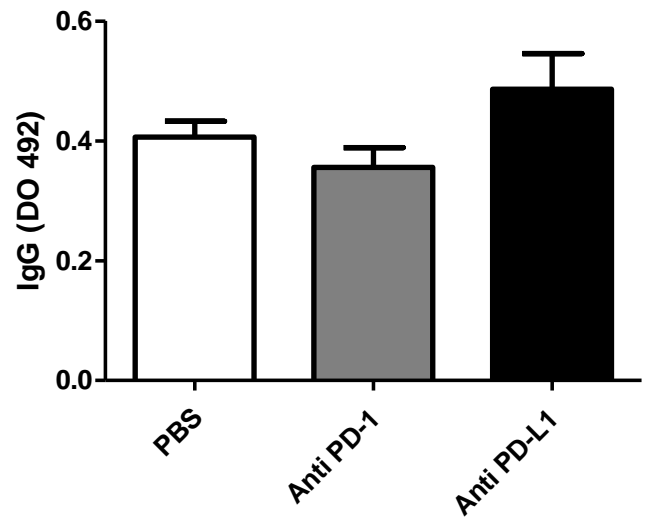

